This document is published in:

Bolzoni, L., Ruiz-Navas, E.M., Neubauer, E., Gordo, E., Mechanical properties and microstructural evolution of vacuum hot-pressed titanium and Ti-6Al-7Nb alloy, Journal of the Mechanical Behavior of Biomedical Materials, May 2012, v. 9, p. 91-99, doi: http://dx.doi.org/10.1016/j.jmbbm.2012.01.015

(C) Elsevier 2012 

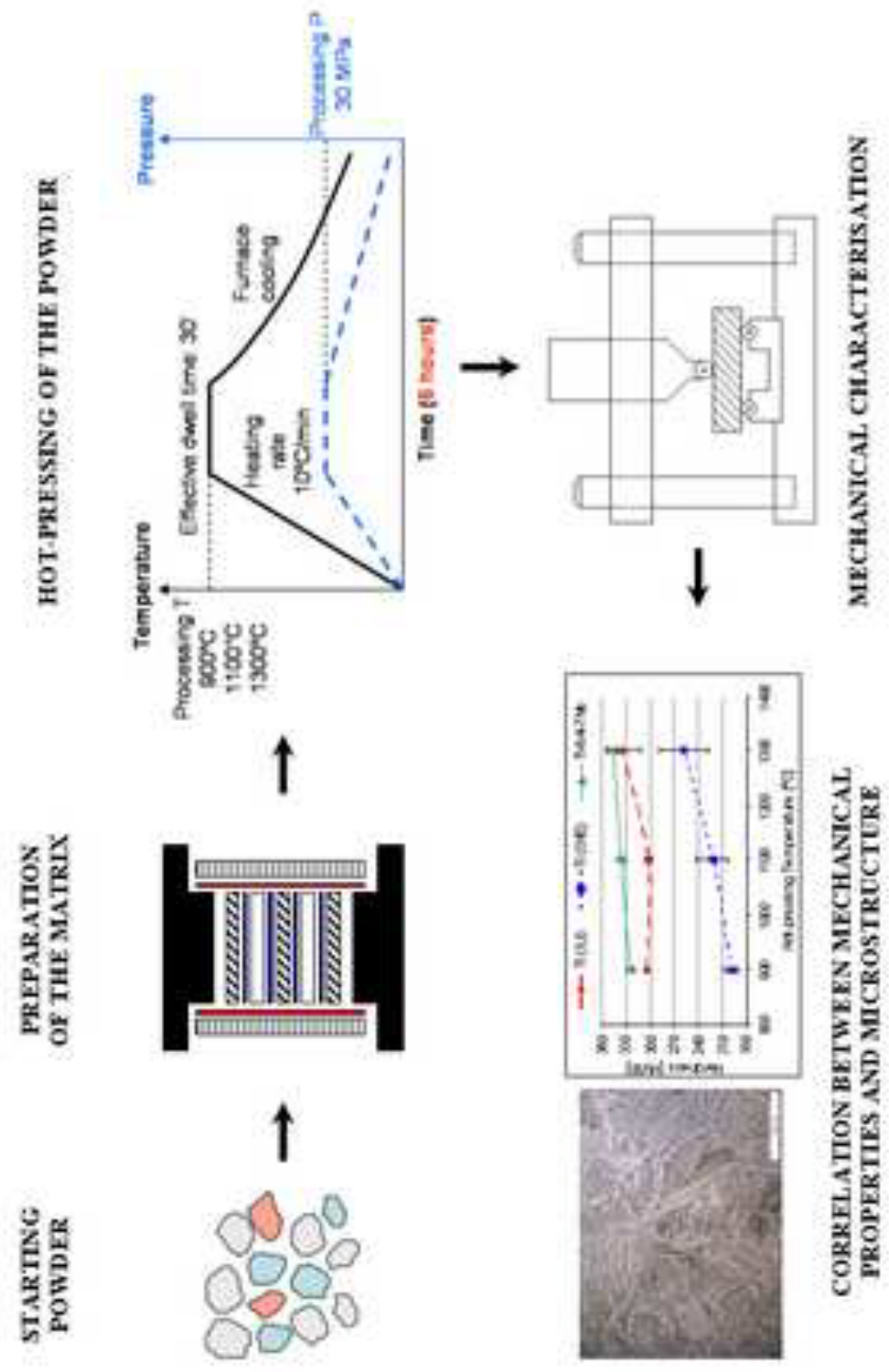

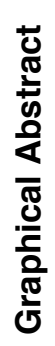


$>$ Hot-pressing is used to make almost fully dense titanium and Ti-6Al-7Nb alloy. $>$ Study of the bending properties of elemental titanium and Ti-6Al-7Nb alloy. $>$ Study of the interaction between titanium and processing tools. $>$ Microstructural evolution of the materials with the processing temperature. 


\title{
Mechanical Properties and Microstructural Evolution of Vacuum Hot-pressed Titanium and Ti-6Al-7Nb Alloy
}

\author{
L. Bolzoni ${ }^{\left({ }^{*}\right)}$, E.M. Ruiz-Navas ${ }^{(1)}$, E. Neubauer ${ }^{(2)}$, E. Gordo ${ }^{(1)}$ \\ (1) Department of Materials Science \\ Universidad Carlos /// de Madrid \\ Avda. de la Universidad 30, 28911 Leganés (Madrid), Spain \\ (2) RHP-Technology GmbH and Co. KG \\ Forschungs- und Technologiezentrum, Gebäude CA \\ A-2444 Seibersdorf, Austria \\ (*) Tel.+34916249482, Fax.+34916249430,e-mail: bolzoni.leandro@gmail.com
}

\begin{abstract}
Hot-pressing is a powder metallurgy process where loose powder is loaded into a mould, usually of graphite, and sintered by the simultaneous application of high temperature and pressure. In this study elemental titanium and Ti-6 Al-7 $\mathrm{Nb}$ alloy powders are hot-pressed under different conditions in order to study the influence of the processing parameters on the microstructure and mechanical properties. The samples are characterised in terms of relative density, microstructure, XRD, percentage of interstitials, three-point bending test and hardness. Relative densities as high as $99 \%$ are obtained, oxygen and carbon content remains almost constant but nitrogen percentage increases. This is due to the interaction with the BN coated mould and leads to the formation of a reacted layer in the surface, composed by different titanium compounds, which greatly affect the mechanical properties. Nevertheless, the removal of this reacted layer leads to an important improvement of the ductility, especially for elemental titanium.
\end{abstract}

Keywords: vacuum hot-pressing, titanium alloys, Ti-6Al-7Nb, bending properties, BNTi interaction

\section{Introduction}

Titanium and titanium-based alloys are principally used for their well-known good balance of properties, like high strength and relative low density (highest specific strength), excellent corrosion resistance and very high biocompatibility. The combination of these characteristics allows the employment of these materials in many 
high-technology industries, namely aerospace and aeronautic industry, medical and dental applications, high corrosive chemical environment and high performance cars. However, the employment of titanium and its alloys in more conventional applications is strongly limited by its cost, both high raw materials cost and high processing cost. This high cost is principally due to the high affinity of titanium for oxygen and other interstitial elements (nitrogen, hydrogen and carbon) which are difficult to eliminate and, even if present in a relative low percentage, modify significantly the mechanical properties (Lütjering, 2003; Donachie, 1988).

Titanium is, generally, preferred to other metallic biomaterials, such as austenitic stainless steel, Co-based alloys (Co-Cr-Mo) and precious metals due to its superior biocompatibility and corrosion resistance in conjunction with low density and an elastic modulus much more similar to that of human bones (Niinomi, 1998). Elemental titanium has been used as a biomedical material since 1950 's and the Ti-6Al-4V alloy has been widely used because, until recently, the mainstream approach taken for the introduction of orthopaedic materials has involved adaptation of existing materials (Long, 1998). Two different generations of new titanium alloy compositions with tailored properties have been developed through the years. The first one includes the Ti$6 \mathrm{Al}-7 \mathrm{Nb}$ and $\mathrm{Ti}-5 \mathrm{Al}-2.5 \mathrm{Fe}$ alloys, which have similar properties to $\mathrm{Ti}-6 \mathrm{Al}-4 \mathrm{~V}$ but are $\mathrm{V}$-free, due to its potential cytotoxicity and adverse reaction with the body tissues. In the second one, enhanced biocompatibility and lower elastic modulus were the two properties searched. Examples of biomedical titanium alloys of the second generation are the $\mathrm{Ti}-13 \mathrm{Nb}-13 \mathrm{Zr}$ and the $\mathrm{Ti}-35 \mathrm{Nb}-5 \mathrm{Ta}-7 \mathrm{Zr}$ alloys. Particularly, the $\mathrm{Ti}-6 \mathrm{Al}-7 \mathrm{Nb}$ alloy was developed by Semlitsch et al. (Semlitsch, 1985) at the end of the nineteen seventies, during the search for the replacement of vanadium with niobium and tantalum, and fabricated by forging bulk material for hip prosthesis stems.

Powder metallurgy techniques allow a reduction in production costs when compared to conventional processing since approximately $90 \%$ of the raw material is used and there is the possibility to avoid or limit machining, being net-shape or near-net-shape techniques (German, 1998). The different $\mathrm{P} / \mathrm{M}$ techniques can be divided into two categories as a function of the temperature at which the consolidation process is done. On one side, cold consolidation, such as the conventional uniaxial pressing which is carried out at room temperature, is followed by the sintering at high temperature. On the other side, in hot consolidation processes the compaction pressure and the temperature are applied simultaneously to the powder. These last processes can produce higher 
relative densities than the achieved with conventional pressing and sintering and, in some cases, are designed to reach full density (Bose, 2003).

Hot-pressing is the simplest hot consolidation process and consists of loading loose powder into a graphite mould, which is coated with a high temperature ceramic material in order to prevent reaction and to promote the mould release. This process is used to shape high melting temperature materials such as tungsten carbide in cobalt matrix, beryllium, diamond tools and composites (Bose, 2003).

Some early hot-pressing or pressure-sintering experiments on titanium (Goetzel, 1971a) and titanium alloy (Goetzel, 1971b; Malik, 1975) powders were carried out during the 70 's of the XX century. In the last decade, the densification behaviour as well as the microstructure obtained with the Ti-6Al-7Nb alloy produced starting from elemental powders (Henriques, 2001) has been investigated.

This work focuses on the behaviour of elemental titanium powders and that of the Ti$6 \mathrm{Al}-7 \mathrm{Nb}$ alloy obtained by mixing a $\mathrm{Nb}: \mathrm{Al}$ :Ti master alloy. The aim of the work is to study the influence of the processing temperature on the relative density, the variation of the mechanical properties ${ }_{2}$ measured by means of three-point bending tests, the content of interstitial elements and the microstructure of elemental titanium and the Ti-6Al-7Nb alloy produced by vacuum hot-pressing. Moreover, the interaction of the powder with the boron nitride coating ${ }_{2}$ applied to the graphite tools to avoid the formation of titanium carbides and favour the release of the hot-pressed components ${ }_{2}$ is also studied.

\section{Experimental Procedure}

In order to carry out the study about the influence of the hot-pressing process parameters, hydride-dehydride (HDH) elemental titanium powder with particle size lower than $26 \mathrm{~m}$ (-500 mesh), and $75 \mathrm{~m}$ (-200 mesh) were supplied by Se-Jong Materials (Ti-SJ) and GfE Gesellschaft für Elektrometallurgie mbH (Ti-GfE), respectively. The Ti-6Al-7Nb alloy was produced by mixing the elemental titanium powder of $75 \mathrm{~m}$ (Ti-GfE) with a powder prepared from a Nb:Al:Ti (60:35:5) master alloy. It is worth mentioning that the master alloy was high energy ball milled in order to reduce its particle size, lowering its maximum particle size to $55 \mathrm{~m}$. The details of the powder preparation route can be found elsewhere (Bolzoni, 2011b). Table 1 shows some characteristics of the powders ready to be used for hot-pressing where particle size distributions were obtained by a laser beam Mastersizer 2000, oxygen (ASTM E 1409) 
and nitrogen (ASTM E 1937) by inert gas fusion method (LECO TC500) and carbon (ASTM E 1941) by combustion technique (LECO CS200).

For hot-pressing experiments, the materials considered were loaded into a die made out of graphite which was lined with a low reactive graphite foil (approximately $0.75 \mathrm{~m}$ thick) to reduce reactions between the powder and the mould. For the preparation of the die, the lower punch is inserted into the cylindrical die cavity and, then, graphite foil coated with BN spray is placed to facilitate mould release and to prevent the direct interaction of titanium powders with the graphite tools at high temperature. Loose powder is poured, a BN coated graphite foil and a graphite disc are placed and, altogether, cold uniaxially pressed at a pressure of approximately $18 \mathrm{MPa}$. These steps are repeated for each one of the powders to be hot-pressed. Finally, the upper punch is inserted into the die cavity and the whole set is put on the equipment. The amount of powder loaded, approximately $75 \mathrm{~g}$, gives as a result a disc of $65 \mathrm{~mm}$ in diameter and 5 $\mathrm{mm}$ in thickness. Figure 1 shows a sketch of the preparation of the graphite mould where the tools used to sinter the powder (graphite mould, graphite discs, BN coated graphite foil, etc.) are labelled.

The materials were pressed under different conditions: $900^{\circ} \mathrm{C}$ and $1100^{\circ} \mathrm{C}$ during 1 hour and $1300^{\circ} \mathrm{C}$ during 30 minutes. Concerning the processing time, by selecting these parameters, an effective dwell time at maximum temperature of 30 minutes is guaranteed since, for the lower temperatures, a delay between the programmed and the measured temperatures was detected. In any case, the parameters employed assure the complete shrinkage of the powder as corroborated by means of the strain gauge measurements recorded by the machine. The control of the temperature is done by means of thermocouples, placed directly in contact with the graphite mould, which guarantees a precision of $\pm 5^{\circ} \mathrm{C}$. The pressure used, which was applied during the heating reaching a maximum pressure of $30 \mathrm{MPa}$, the heating rate of $10^{\circ} \mathrm{C} / \mathrm{min}$ and the vacuum level of $10^{-1}$ mbar were kept constant in the diverse experiments carried out.

Once pressed, the specimens were taken out of the matrix, sandblasted to clean the surface and characterized in terms of relative density by Archimedes' principle and microstructural analysis by means of optical and electronic microscopy in previously ground (SiC-320), polished (silica after diamond $9 \mu \mathrm{m}$ ) and etched (Kroll) specimens Chemical analyses (oxygen, nitrogen and carbon), X-ray analysis as well hardness measurements were performed. From the discs obtained, rectangular shaped specimens were cut in order to obtain samples to be submitted to the three-point bending test 
(ASTM B528) for mechanical characterisation. Some of these specimens were also previously ground to remove the surfaces which had been in contact with the BN coating of the graphite foil during the compaction. In this way it is possible to detect eventual reactions occurred between the coating and the powder and to study how the outer layer affects the mechanical properties of the materials.

\section{Results and Discussion}

Figure 2 shows the relative density obtained for each one of the processed materials as a function of the temperature where for its calculation the values of the density of the wrought materials were used $\left(4.51 \mathrm{~g} / \mathrm{cm}^{3}\right.$ for elemental titanium and $4.52 \mathrm{~g} / \mathrm{cm}^{3}$ for Ti$6 \mathrm{Al}-7 \mathrm{Nb})$.

As it can be seen in Figure 2, the relative density increases continuously for both the elemental titanium powders as well as for the Ti-6Al-7Nb alloy where the most important increment corresponds to the $\mathrm{Ti}(\mathrm{SJ})$ powder, being $1 \%$ every $200^{\circ} \mathrm{C}$. Moreover, it is interesting to notice that even thought of smaller particle size, which should favour the densification of the material due to the greater specific surface area, $\mathrm{Ti}(\mathrm{SJ})$ powder reaches lower values compared to $\mathrm{Ti}(\mathrm{GfE})$. On the other side, it can also be seen that the ratio at which the relative density of Ti(SJ) increases with the temperature is higher with respect to Ti(GfE). This could indicates that the lower the processing temperature, the greater the influence of the oxide layer present on the surface of the powder particles which, therefore, hinders the densification of the material. This effect is, clearly, favoured by a smaller particle size or a higher specific surface area, which results in a higher oxygen content, as it can be corroborated by means of the chemical analysis shown in Table 1. Finally, the relative density values obtained range from $97 \%$ to $99 \%$ and, thus, are higher than the typical density of $95 \%$ obtained by conventional pressing and sintering combined with the blended elemental approach (Abkowitz, 1986; Froes, 2002; Bolzoni, 2010; Bolzoni, 2011a).

In Figure 3 the evolution of the size, morphology and distribution of the residual porosity with the temperature by means of the micrograph of representative example of Ti(GfE) elemental titanium samples are presented.

Analysing Figure 3 it can be seen that the elemental titanium specimens show a very small porosity, smaller than approximately $10 \mu \mathrm{m}$, and the percentage is much higher in the specimens processed at $900^{\circ} \mathrm{C}$ (Figure 3a) and, then, disappears with the increment of the sintering temperature (Figure $3 b$ ). These results are in complete agreement with 
the density values previously shown in Figure 2. Moreover, it can be stated that the porosity at low temperature is not only higher but also much more irregular in shape and it becomes more and more spherical passing from $900^{\circ} \mathrm{C}$ to $1300^{\circ} \mathrm{C}$.

The evolution of the microstructural features with hot-pressing temperature is shown in Figure 4 by means of micrographs taken on specimens etched by means of Kroll's reactant. It is worth mentioning that the micrograph of elemental titanium refers to $\mathrm{Ti}(\mathrm{SJ})$ but they are representative also for $\mathrm{Ti}(\mathrm{GfE})$ since the microstructure is composed exclusively by $\alpha$ grains and the only difference is the slightly bigger grain size of $\mathrm{Ti}(\mathrm{GfE})$ in comparison to $\mathrm{Ti}(\mathrm{SJ})$.

Concerning the evolution of the microstructure of elemental titanium (Figure 4 a-c) with the hot-pressing temperature, it can be seen that there is a grain coarsening with the increase in the processing temperature and, therefore, a lower amount of grain boundaries for higher temperatures. It is worth mentioning that the grain growth is more marked for Ti(SJ) due to the smaller particle size. On the other side, for the Ti-6Al-7Nb alloy, it can be noticed that the processing temperature of $900^{\circ} \mathrm{C}$ (Figure $4 \mathrm{~d}$ ), which is lower than the beta transus of this alloy, is not high enough to guarantee the complete dissolution of the master alloy particles in the titanium matrix and, therefore, to develop the typical Widmanstätten microstructure. The increment of the hot-pressing temperature to $1100^{\circ} \mathrm{C}$ leads to a much more uniform microstructure (Figure 4e) but the distribution of the alloying elements is not completely uniform as corroborated by means of EDS analysis. A further increment of the temperature to $1300^{\circ} \mathrm{C}$ permits to obtain a homogeneous distribution of the alloying elements and the typical microstructure of $\alpha+\beta$ titanium alloys composed by $\alpha$ grains and $\alpha+\beta$ lamellae (Figure 4f).

Concerning chemical analysis results, in the case of oxygen and carbon a single value is reported in Figure 5 since no big differences were detected between the ground and not ground specimens. On the other side, nitrogen content has been split up for machined and not machined samples since the results obtained where quite different as clearly visible in Figure 6.

As it can be seen in Figure 5, oxygen content is almost constant with the temperature for both elemental titanium materials and for the Ti-6Al-7Nb alloy. The most important point is that there is always some oxygen pick-up for the elemental titanium powders whereas there is not increment of the amount of oxygen dissolved for the Ti-6Al-7Nb alloy in comparison to the values of the starting powders (Figure 5). Moreover, it can 
also be stated that this oxygen pick-up is slightly more pronounced for $\mathrm{Ti}(\mathrm{SJ})$ in agreement with the finer particle size of the starting powder, which will have a higher specific area and a greater amount of oxygen adsorb onto the surface of the powder particles. Finally, comparing the absolute values, it can be seen that Ti(SJ) specimens have higher oxygen content as a consequence of the greater percentage already dissolved in the starting powder.

About carbon content (Figure 5), the measurements carried out on each specimen reveal that carbon percentage increases with the processing temperature where the increment is more marked from $1100^{\circ} \mathrm{C}$ to $1300^{\circ} \mathrm{C}$ than from $900^{\circ} \mathrm{C}$ to $1100^{\circ} \mathrm{C}$. The carbon pick-up is mainly due to the carbon rich atmosphere produced by the graphite tools at high temperature and that is why it increases with the increment of the hot-pressing temperature. Nonetheless, carbon values obtained are lower than $0.08 \%$, which is the value required for all the elemental titanium grades and titanium alloys (Boyer, 1998). Concerning nitrogen content (Figure 6), it can be noticed that the amount of this interstitial element increases with the processing temperature and the increment is much higher between $1100^{\circ} \mathrm{C}$ and $1300^{\circ} \mathrm{C}$ for both ground and not ground specimens. Moreover, it is interesting to point out the great difference in nitrogen content between machined and not machined samples which indicates that there has been reaction between the specimens and the BN coating of the graphite foil and, therefore, nitrogen pick-up. Comparing the titanium powders, nitrogen percentage is slightly higher in $\mathrm{Ti}(\mathrm{GfE})$ than in $\mathrm{Ti}(\mathrm{SJ})$ at $900^{\circ} \mathrm{C}$ and $1100^{\circ} \mathrm{C}$ and much higher at $1300^{\circ} \mathrm{C}$ for not ground samples but it is almost equal in the ground ones.

To confirm the interaction between the $\mathrm{BN}$ coating of the matrix and the titanium powders, SEM analysis of the surface of the specimens was carried out. Since the behaviour found during the characterisation does not depend on the type of the starting powder, the results of Ti(GfE) samples, which can be considered representative of the whole materials studied, are reported in Figure 7.

The general behaviour can be summarised as follows: at $900^{\circ} \mathrm{C}$ (Figure 7 a) there is no reaction layer, probably due to the relative low energy available for the decomposition of $\mathrm{BN}$ and the diffusion of boron and nitrogen through titanium. Nonetheless, based on the chemical analysis, it can be stated that nitrogen diffuses through titanium because in all the cases nitrogen pick-up is observed and the diffusion is supposed to be faster with the raising of the processing temperature (Wasilewski, 1954). At $1100^{\circ} \mathrm{C}$ (Figure $7 \mathrm{~b}$ ), an irregular dark layer varying between $5 \mathrm{~m}$ and $10 \mathrm{~m}$ in thickness is clearly visible 
and at $1300^{\circ} \mathrm{C}(($ Figure $7 \mathrm{c})$ this layer is already well formed, relatively uniform and thicker $(20 \mathrm{~m})$. Energy dispersive X-ray analysis indicates that this layer is composed by titanium and nitrogen (on average 6.5 wt.\% or 19.5 at.\%) but boron could not be detected due to the intrinsic detection limits of the equipment.

To better understand the nature of the reaction that takes place between the titanium powder and the BN coating, XRD analysis of the surface of the hot-pressed samples was carried out. The XRD patterns of the surface of the specimens shown in Figure 7 are presented in Figure 8.

It is worth mentioning that the XRD patterns shown in Figure 8 refer to Ti(GfE) elemental titanium since no significant differences are found either when using an elemental titanium powder with lower particle size, Ti(SJ), or a titanium alloy (Ti-6Al$7 \mathrm{Nb}$ ) and the phases detected on the surface of the specimens are always the same. This is most probably due to the higher affinity of titanium for both boron and nitrogen than that of aluminium or niobium.

On the bases of the XRD results (Figure 8), it can be stated that, at $900^{\circ} \mathrm{C}$, the powder picks up some nitrogen from the BN coating forming an interstitial solid solution of nitrogen in titanium $\alpha-\operatorname{Ti}(\mathrm{N})$. Its peaks practically coincide with that of elemental alpha titanium and are marked in the XRD pattern of the powder sintered at $900^{\circ} \mathrm{C}$. When raising the temperature at $1100^{\circ} \mathrm{C}$ the amount of nitrogen diffusing into the titanium matrix increases. It is well known that the increasing the nitrogen content in titanium induces an increment of both the "a" and "c" parameters of the unit cell (Jaffee, 1958). This is reflected in a slight displacement of the peaks of titanium alpha toward lower diffraction angle which can be seen in the XRD patterns of the materials processed at $900^{\circ} \mathrm{C}$ and at $1100^{\circ} \mathrm{C}$ (Figure 8). Moreover, the increment of nitrogen seems to be high enough to promote the formation of $\mathrm{Ti}_{2} \mathrm{~N}$ and $\mathrm{TiN}$ compounds. At $1100^{\circ} \mathrm{C}$ also boron, which is not detected at $900^{\circ} \mathrm{C}$, is diffusing toward the titanium powder forming the stable compound TiB. The absence of boron or titanium boride at $900^{\circ} \mathrm{C}$ is mainly due to the higher solubility of nitrogen in titanium with respect to that of boron, being, in beta titanium, as high as 22 at.\% (N) and lower than 0.2 at.\% (B) (Murray, 1987). In the $\mathrm{XRD}$ of the powder sintered at $1100^{\circ} \mathrm{C}$ some BN is identified, which most probably was not removed when cleaning the surface of the specimens by sandblasting. From the $\mathrm{XRD}$ of the specimens produced at $1300^{\circ} \mathrm{C}$, it seems that the higher amount of thermodynamic energy available leads to a faster diffusion of nitrogen from the surface toward the titanium matrix since the relative intensity of the solid solution and TiN 
diminish. On the other side, boron content in the surface increases allowing the formation of $\mathrm{TiB}_{2}$ as well as $\mathrm{TiB}$. It is worth mentioning that the abnormally strong relative intensity of the TiB peak at $60.6^{\circ}$, which correspond to the (020) plane, is due to the preferred growth direction of TiB which is [010] (Faran, 2000). These results are in agreement with the binary phase diagram (Murray, 1987) and the Ti-B-N ternary system where, according to the calculation of chemical equilibrium in the $\mathrm{BN}-\mathrm{Ti}$ system and investigation about the reactions occurring at the $\mathrm{BN}-\mathrm{Ti}$ interface (Benko, 1996), diffusion of $\mathrm{BN}$ towards titanium leads to the formation of new phases, namely, $\mathrm{TiB}_{2}$ (directly at the interface) and TiN (further from the interface towards the material) already at $950^{\circ} \mathrm{C}$. Moreover, Faran et al. (Faran, 2000) studied the interaction of BN samples immersed in loose titanium powder and subjected to an annealing treatment at $1000-1200^{\circ} \mathrm{C}$ obtaining similar results. In particular, they found that the reaction zone is constituted by $\mathrm{Ti}$ borides ( $\mathrm{TiB}$ and $\left.\mathrm{TiB}_{2}\right)$ and nitrides $\left(\mathrm{TiN}_{1-\mathrm{x}}\right.$ and $\left.\mathrm{TiN}\right)$. Other works have been done considering the hot-pressing technique to obtain porous titanium compacts $(\mathrm{Oh}, 2003)$ where a $\mathrm{BN}$ coating was used to avoid the reaction between graphite and the powder but none of them reports any kind of interaction.

Figure 9 shows representative examples of the load-deflection curve for each of the materials studied and, in particular, the curve shown refer to the specimens hot-pressed at $1300^{\circ} \mathrm{C}$ whose surface was removed. From the curves shown in Figure 9 it can be seen that, with the relative density values obtained by means of the hot-pressing techniques (Figure 2), the flexural modulus of the three materials is very similar. It is worth mentioning that, generally, the hot-pressed samples behave as brittle materials and the samples fail without any appreciable plastic deformation. However, in some cases and, especially, for Ti(GfE) the specimens show a pronounced plastic deformation before fracture (Figure 9). Since the formula specified in the ASTM B528 standard for the calculation of the transverse rupture strength is applicable to relatively brittle materials, the $\sigma_{0.2}$ values are considered and they are represented for each material as a function of the processing temperature and of the grinding step in Figure 10. As it can be seen in Figure 10, the strength of Ti(SJ) ground and not ground specimens always decrease with the processing temperature where the drop of the strength should be related to microstructural features as well as to the chemical analysis; in particular, the grain growth caused by the increment of the processing temperature and the increment of the nitrogen percentage (Figure 6). Concerning Ti(GfE), the strength stays 
almost constant with the hot-pressing temperature and regardless of the removal of the outer surface up to $1100^{\circ} \mathrm{C}$, point from which the strength decreases for not ground samples and it increases for ground specimens where this behaviour is justified by the lower grain growth and the chemical analysis. Comparing the $\sigma_{0.2}$ values of $\mathrm{Ti}(\mathrm{SJ})$ and $\mathrm{Ti}(\mathrm{GfE})$, it can be noticed that $\mathrm{Ti}(\mathrm{SJ})$, normally, reaches higher strength due to the smaller grain size and the strengthening effect of oxygen, whose percentage is significantly higher for $\mathrm{Ti}(\mathrm{SJ})$ in comparison to $\mathrm{Ti}(\mathrm{GfE})$ as shown in Figure 5. The strength of Ti-6Al-7Nb increases from $900^{\circ} \mathrm{C}$ to $1100^{\circ} \mathrm{C}$ and then decreases for not ground specimens whereas the strength increases continuously with the hot-pressing temperature after grinding (Figure 10). For Ti-6Al-7Nb, the increment of the strength is related to the diffusion of the alloying elements and, therefore, to the development of the typical laminar $\alpha+\beta$ microstructure obtained by the slow cooling into the two phase region from above the beta transus. For the not ground Ti-6Al-7Nb specimens processed at $1300^{\circ} \mathrm{C}$ the effect of the homogenisation of the microconstituents is overcome by the presence of the fragile reacted layer (Figure 7c) which justifies the drop of the strength. With the exclusion of some exception, such as Ti(SJ) hot-pressed at $900^{\circ} \mathrm{C}$ or $1100^{\circ} \mathrm{C}$, the strength of Ti-6Al-7Nb is, normally, higher in comparison to that of elemental titanium due to the effect of the alloying elements. Finally, the $\sigma_{0.2}$ values obtained for the elemental titanium and Ti-6Al-7Nb samples obtained by means of hot-pressing are, generally, comparable or higher with respect to the value specified for wrought Ti-6Al-7Nb medical devices (935-995 MPa) (Henry, 2009).

Table 2 reports the values of maximum bending strength and flexural strain obtained by means of three-point bending test where it can be seen that, in most of the cases, the transverse rupture strength and maximum bending strength coincides with the $\sigma_{0.2}$ values as explained before. The greatest differences are found for Ti(GfE) where the maximum bending strength is, usually, higher than the yield strength.

Regarding the flexural strain (Table 2), the ductility always decreases with the increment of the temperature for both ground and not ground specimens made out from elemental titanium powders whilst it increases from $900^{\circ} \mathrm{C}$ to $1100^{\circ} \mathrm{C}$ and then decreases for the Ti-6Al-7Nb alloy. Nevertheless, for the three materials the flexural strain is higher after grinding where this is especially remarkable in the case of elemental titanium (GfE) where flexural strain value as high as $25 \%$ were obtained. The increment of both strength and flexural strain after grinding is clearly due to the removal 
of the brittle outer layer which contains either a solid solution of nitrogen in titanium or titanium nitrides and borides (Figure 7). It has been demonstrated that nitrogen has a great strengthening effect on titanium, even more than oxygen, and correspondingly decreases the ductility (Jaffee, 1949).

Finally, Figure 11 plots the results of the hardness test where the mean values presented are not affected by the presence of the reacted layer as hardness measurements were taken in the cross-section of the samples.

As it can be seen in Figure 11, the hardness of elemental titanium and Ti-6Al-7Nb hotpressed specimens increases with the processing temperature due to the increment of the relative density (Figure 2) and the amount of interstitials dissolved. Moreover, the hardness of Ti(SJ) is significantly higher compared to Ti(GfE) most probably due to the smaller grain size and the higher oxygen content found since this element harden titanium (Jaffee, 1949). In comparison to the respective wrought materials, the hardness of Ti(SJ) is always, at least, $50 \mathrm{HV}$ higher the CP grade 4 elemental titanium (253 HV) due to the greater amount of interstitials dissolved, especially oxygen (Figure 5) and, most probably the fine microstructure. In the case of Ti(GfE), the hardness is higher only for the specimens hot-pressed at $1300^{\circ} \mathrm{C}$ due to the chemical analysis and the microstructural features. Concerning the Ti-6Al-7Nb alloy, hot pressed samples is characterised by hardness values somewhat higher in comparison to the value of the IMI 367 (270-290 HV) (Henry, 2009) and similar to that specified by Semlitsch et al. (350 HV) (Semlitsch, 1985). This is, once again, due to the higher amount of oxygen of the hot-pressed specimens (approximately $0.4 \mathrm{wt} . \%$ ) in comparison to the wrought material (normally $0.2 \mathrm{wt} . \%$ ) and the characteristics of the microconstituents like mean $\alpha$ grain size as well as relative amount and distribution of $\alpha+\beta$ lamellae.

\section{Conclusions}

This study demonstrates that hot-pressing can be applied in order to produce fully dense titanium and titanium alloy products starting from irregular powders with different characteristics and obtaining the typical microstructure of the respective wrought materials obtained by slow cooling from above the beta transus.

The process studied is suitable to produce fully-dense and homogeneous Ti-6Al-7Nb titanium alloy components starting from a master alloy and, therefore, much cheaper than a prealloyed powder which could reduce the final cost of this alloy. 
The mechanical properties of blended elemental pressings are greatly influenced from the processing temperature due to combined effect of the interstitials, grain growth and interaction with the BN coating and, as expected, the Ti-6Al-7Nb alloy has, normally, higher strength compared to elemental titanium. Nevertheless, it has been demonstrated that the elimination of the outer layer by grinding is beneficial in order to increase both the maximum bending strength and the flexural strain.

This study further confirms that when titanium is placed in contact with $\mathrm{BN}$ at high temperature they will react promoting the diffusion of nitrogen and boron through the titanium matrix leading to the formation of different stoichiometric compounds such as titanium nitrides and borides depending on the temperature employed.

\section{Acknowledgements}

The authors are thankful for the financial support from Comunidad de Madrid through the ESTRUMAT (S-2009/MAT-1585) project and from the Spanish Ministry of Education through the R\&D Project MAT2009-14448-C02-02.

\section{References}

Abkowitz S. and Rowell, D., "Superior Fatigue Properties for Blended Elemental P/M Ti-6Al-4V", Journal of Metals, pp. 36-39, 1986

Benko, E., "Chemical Reactions Occurring at a BN-AgTi Interface", Ceramics International, vol. 22, pp. 219-222, 1996

Bolzoni, L., Esteban, P. G., Ruiz-Navas, E. M. and Gordo, E., "Influence of Powder Characteristics on Sintering Behaviour and Properties of PM Ti Alloys Produced from Prealloyed Powder and Master Alloy", Powder Metallurgy, vol. 54, pp. 543550,2011

Bolzoni, L., Ruiz-Navas, E. M, Neubauer and Gordo, E., "Inductive Hot-pressing of Titanium and Titanium Alloy Powders", Materials Chemistry and Physics, doi:10.1016/j.matchemphys.2011.10.034

Bolzoni, L., Esteban, P. G., Ruiz-Navas, E. M. and Gordo, E., "Biomedical Ti-6Al-7Nb Titanium Alloy Produced by P/M Techniques" in PM 2010 World Congress. vol. PM Biomaterials III, Florence, Italy, EMPA, 2010

Bose, A. and Eisen, W. B., Hot Consolidation of Powders \& Particulates. Princeton, USA, Metal Powder Industries Federation, pp. 1-88, 2003 
Boyer, R., Welsch, G. and Collings, E. W., "Materials Properties Handbook: Titanium Alloys", 2nd ed, ASM-International, Ed. Ohio, USA, 1998

Donachie, M. J., Titanium. A Technical Guide, ASM International, pp. 1-223, 1988

Faran, E., Gotman, I. and Gutmanas, E. Y., "Experimental Study of the Reaction Zone at Boron Nitride Ceramic-Ti Metal Interface", Materials Science and Engineering A, vol. 288, pp. 66-74, 2000

Froes, F. H., Ivasishin, O.M., Moxson, V. S., Savvakin, D. G., Bondareva, K.A. and Demidik, A. M., "Cost-effective Synthesis of Ti-6Al-4V Alloy Components via the Blended Elemental P/M Approach" in Symposium on TMS Symposium on High Performance Metallic Materials for Cost Sensitive Applications, Seattle, WA, 2002

German, R. M., Powder Metallurgy of Iron and Steel, John Wiley \& Sons, Inc., 1998 Goetzel, C. G. and de Marchi, V. S., "Electrically Activated Pressure Sintering (Spark Sintering) of Titanium Powders", Powder Metallurgy International, vol. 3, pp. 8087,1971

Goetzel, C. G. and de Marchi, V. S., "Electrically Activated Pressure Sintering (Spark Sintering) of Titanium-aluminium-vanadium Alloy Powders", Modern Developments in Powder Metallurgy, vol. 4, pp. 127-150, 1971

Henriques, V. A. R., Bellinati, C. E. and da Silva, C. R. M., "Production of Titanium Alloys for Medical Implants by Powder Metallurgy", Key Engineering Materials vol. Advanced Powder Technology II pp. 443-448, 2001

Henry D., Materials and Coatings for Medical Devices: Cardiovascular. Ohio, USA, ASM International, pp. 151-186, 2009

Jaffee R. I. and Campbell, I. E., "The Effect of Oxygen, Nitrogen and Hydrogen on Iodide Refined Titanium", Transactions of the American Institute of Mining and Metallurgical Engineers, vol. 185, pp. 646-654, 1949

Jaffee, R. I., "The Physical Metallurgy of Titanium Alloys", Progress in Metal Physics, vol. 7, pp. 65-163, 1958

Long, M. and Rack, H. J., "Titanium Alloys in Total Joint Replacement - A Materials Science Perspective", Biomaterials, vol. 19, pp. 1621-1639, 1998

Lütjering, G. and Williams, J. C., Titanium: Engineering Materials and Processes, 1st ed. Manchester, UK, Springer, pp. 1-356, 2003

Malik, R. K., "Vacuum Hot Pressing of Titanium Alloy Powders", Progress in Powder Metallurgy, vol. 31, pp. 277-288, 1975 
Murray, J. L., Phase Diagrams of Binary Titanium Alloys, 1st ed, ASM International, pp. 1-345, 1987

Niinomi, M., "Mechanical Properties of Biomedical Titanium Alloys", Materials

Science and Engineering A, vol. 243, pp. 231-236, 1998

Oh, I-H., Nomura, N., Masahashi, N. and Hanada, S., "Mechanical Properties of Porous

Titanium Compacts Prepared by Powder Sintering", Scripta Materialia, vol. 49, pp.

1197-1202, 2003

Semlitsch, M., Staub, F. and Weber H., "Titanium-aluminium-niobium Alloy

Development for Biocompatible, High Strength Surgical Implants",

Biomedizinische Technik/Biomedical Engineering, vol. 30, pp. 334-339, 1985

Wasilewski, R. J. and Kehl, I., "Diffusion of Nitrogen and Oxygen in Titanium", Journal Institute of Metals, vol. 83, pp. 94-104 1954-1955 
List of Table

Table 1. Particle size distribution and chemical analysis of the starting powders.

Table 2. Maximum bending strength and flexural stain of elemental titanium and Ti$6 \mathrm{Al}-7 \mathrm{Nb}$ hot-pressed specimens.

\section{List of Figure Caption's}

Figure 1. Sketch of the preparation of the mould for hot-pressing of titanium and titanium alloys.

Figure 2. Relative density of elemental titanium and Ti-6Al-7Nb specimens as a function of the hot-pressing temperature.

Figure 3. Representative example of the details of the residual porosity found in hotpressed samples, $\mathrm{Ti}(\mathrm{GfE})$ : a) $900^{\circ} \mathrm{C}$ and b) $1300^{\circ} \mathrm{C}$.

Figure 4. SEM microstructure analysis for hot-pressed elemental titanium, $\operatorname{Ti}(\mathrm{SJ})$ : a) $900^{\circ} \mathrm{C}$, b) $1100^{\circ} \mathrm{C}$ and c) $1300^{\circ} \mathrm{C}$; and for hot-pressed Ti-6Al-7Nb: d) $900^{\circ} \mathrm{C}$, e) $1100^{\circ} \mathrm{C}$ and f) $1300^{\circ} \mathrm{C}$.

Figure 5. Oxygen and carbon content of elemental titanium and $\mathrm{Ti}-6 \mathrm{Al}-7 \mathrm{Nb}$ specimens as a function of the hot-pressing temperature.

Figure 6. Nitrogen content of ground and not ground elemental titanium and Ti-6Al$7 \mathrm{Nb}$ specimens as a function of the hot-pressing temperature.

Figure 7. Backscattered electron SEM images of the surfaces of Ti(GfE) elemental titanium specimens in contact with the $\mathrm{BN}$ coating processed at: a) $900^{\circ} \mathrm{C}$, b) $1100^{\circ} \mathrm{C}$ and c) $1300^{\circ} \mathrm{C}$. 
Figure 8. XRD patterns of the surface of the hot-pressed Ti(GfE) elemental titanium hot-pressed specimens.

Figure 9. Representative examples of load-deflection curve for elemental titanium and Ti-6Al-7Nb hot-pressed specimens.

Figure 10. Variation of the yield strength of elemental titanium and Ti-6Al-7Nb hotpressed specimens, determined by three-point bending tests, as a function of the hotpressing temperature.

Figure 11. Hardness of elemental titanium and Ti-6Al-7Nb specimens as a function of the hot-pressing temperature. 

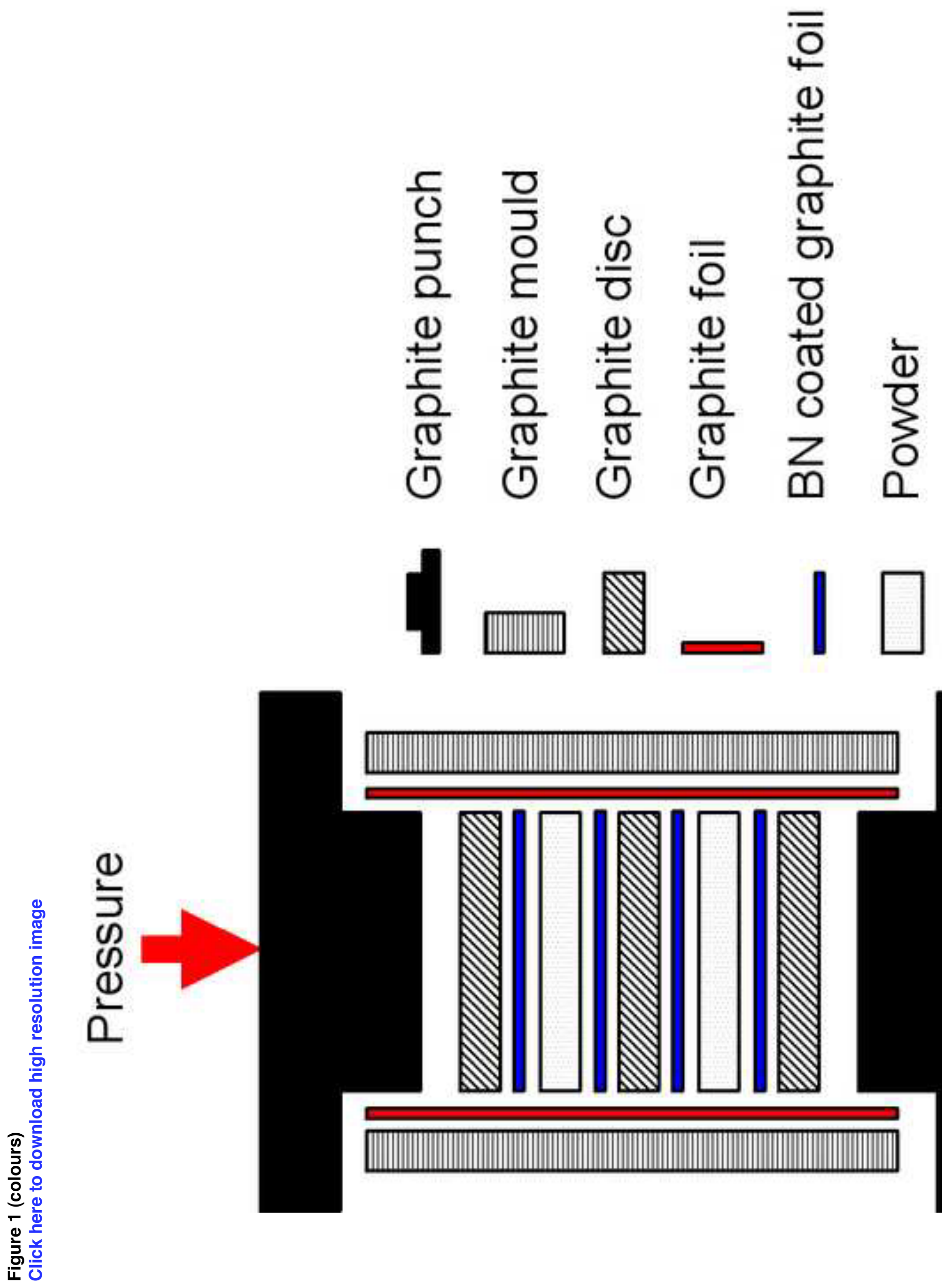

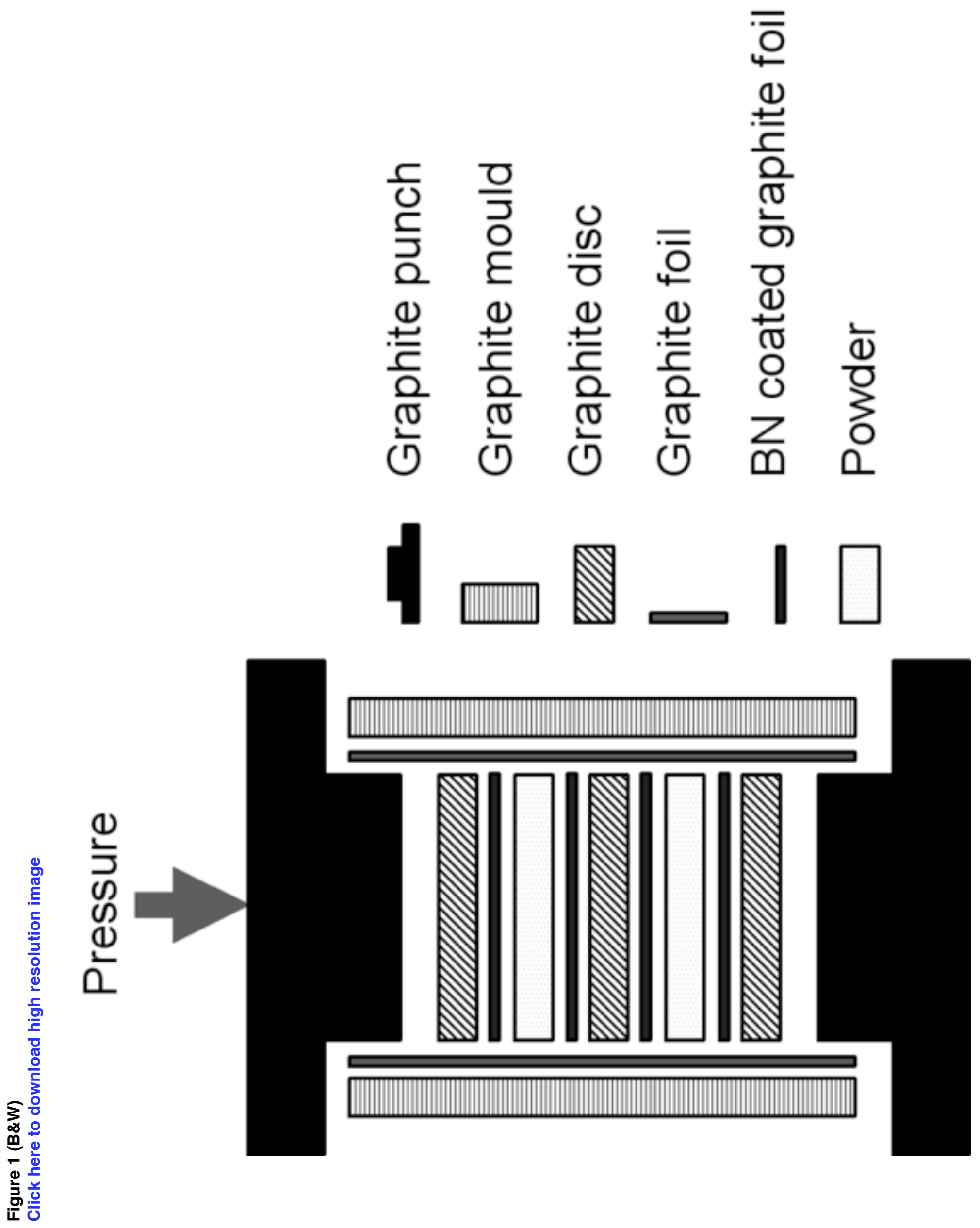


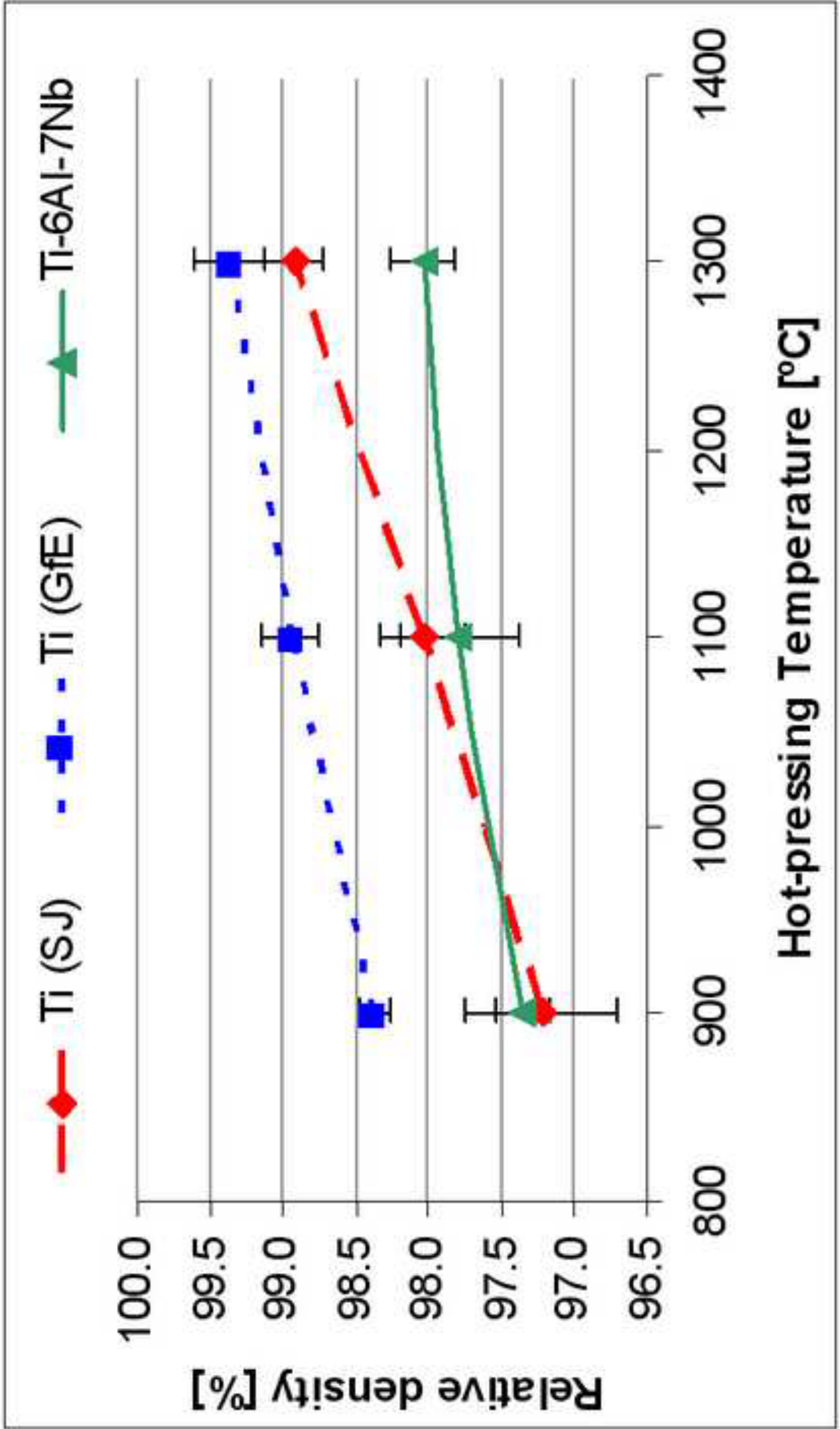




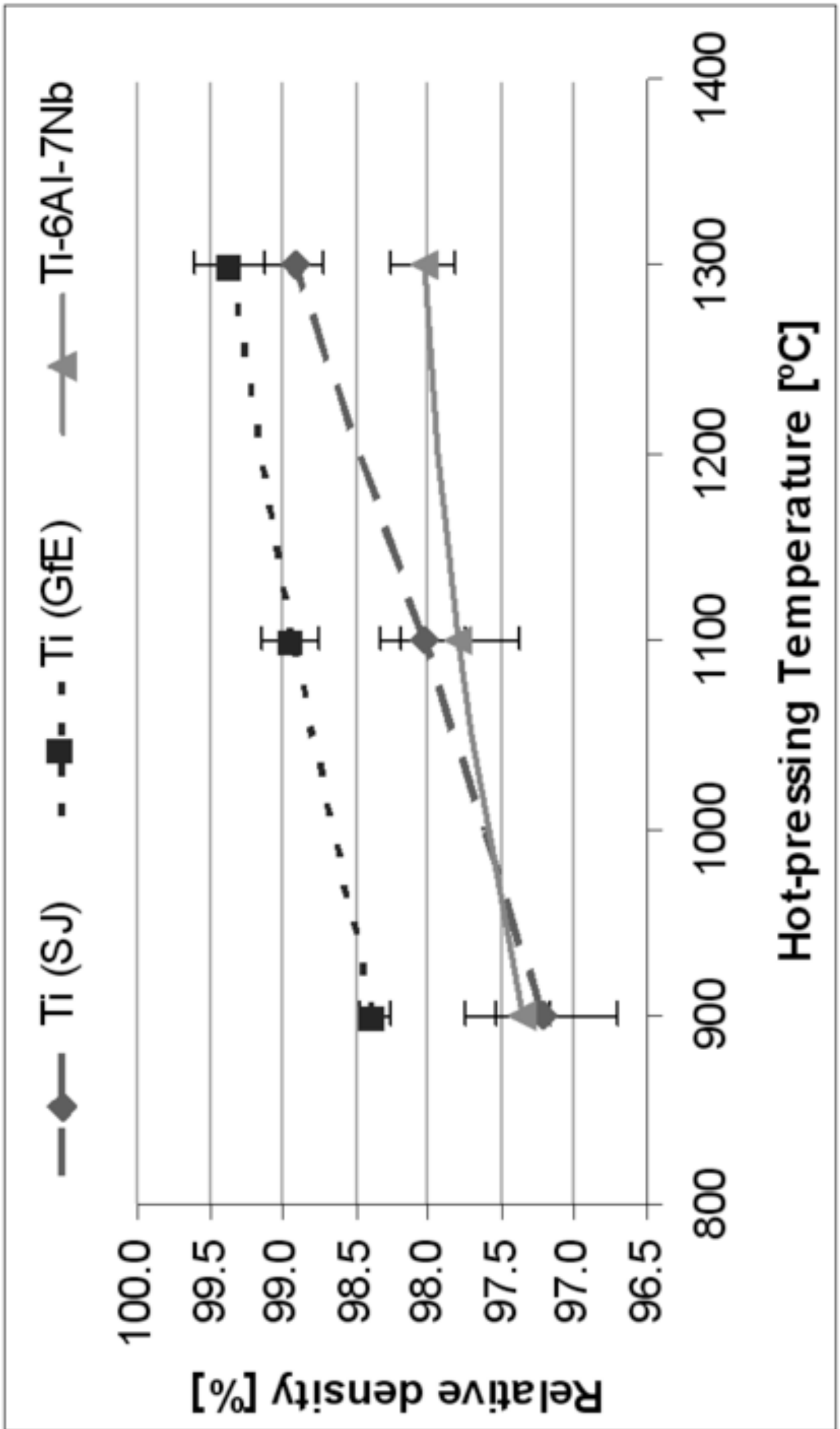


ACCEPTED MANUSCRIPT

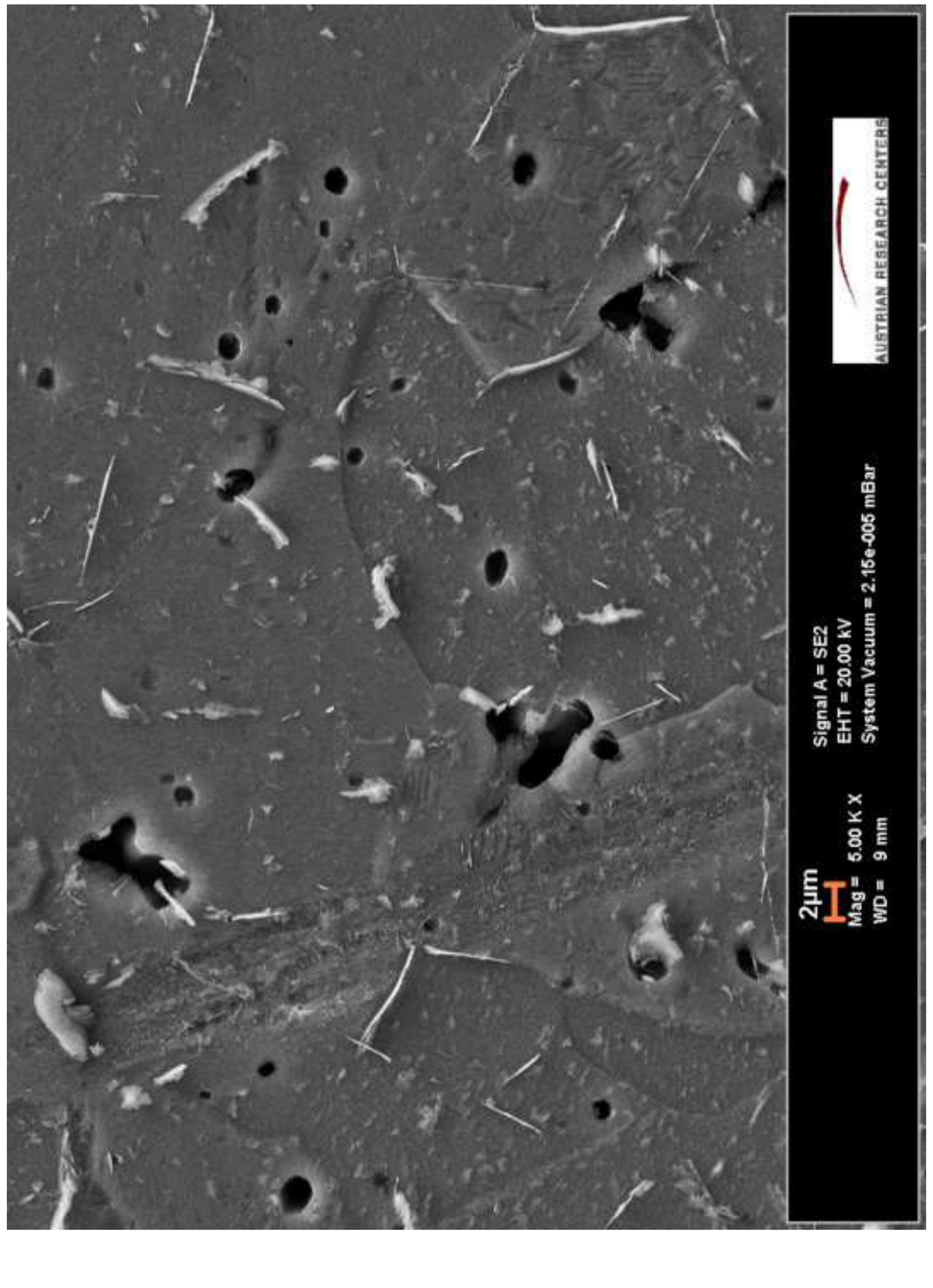




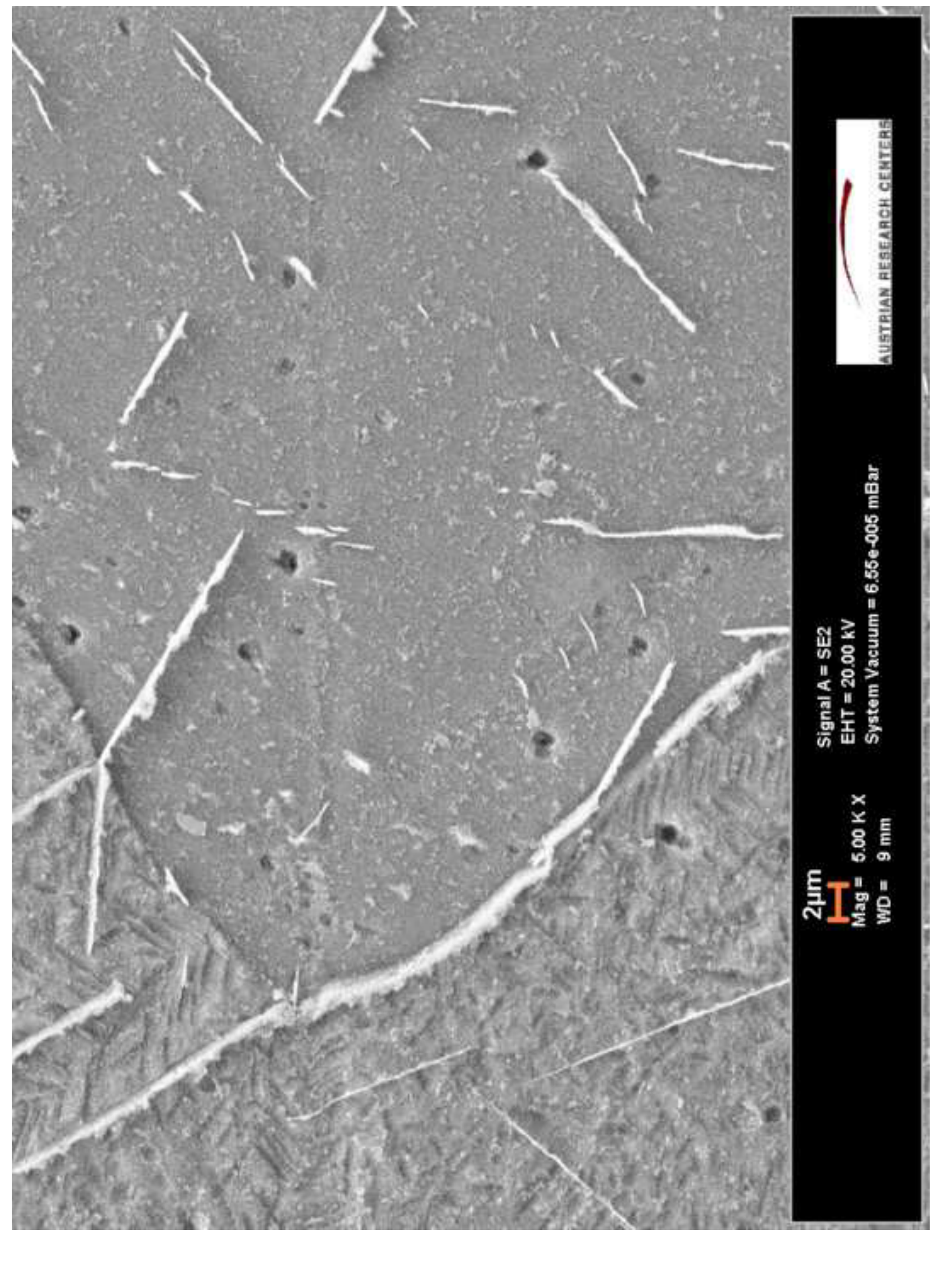



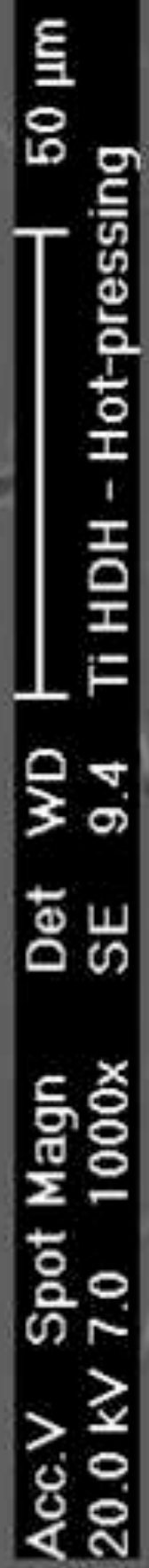

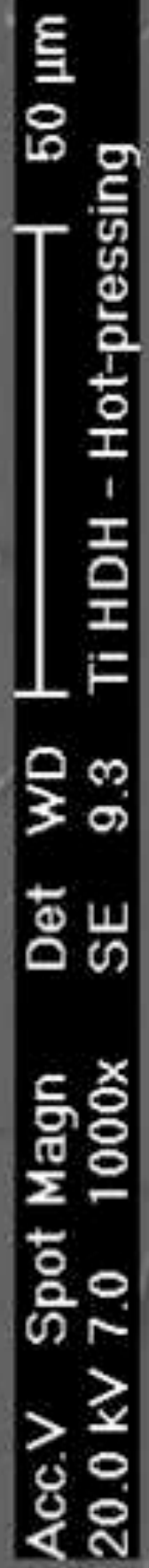
ACCEPTED MANUSCRIPT

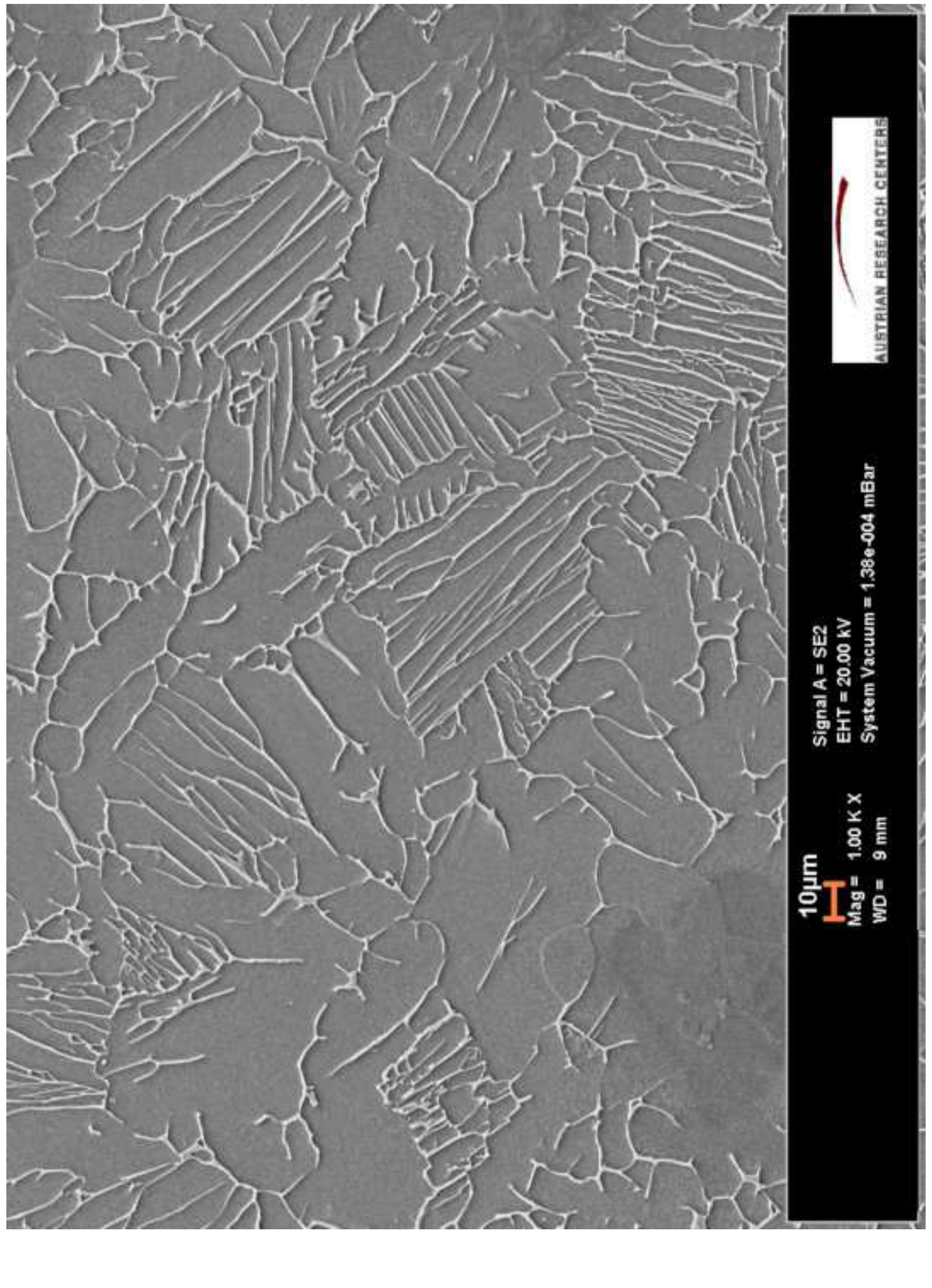


ACCEPTED MANUSCRIPT

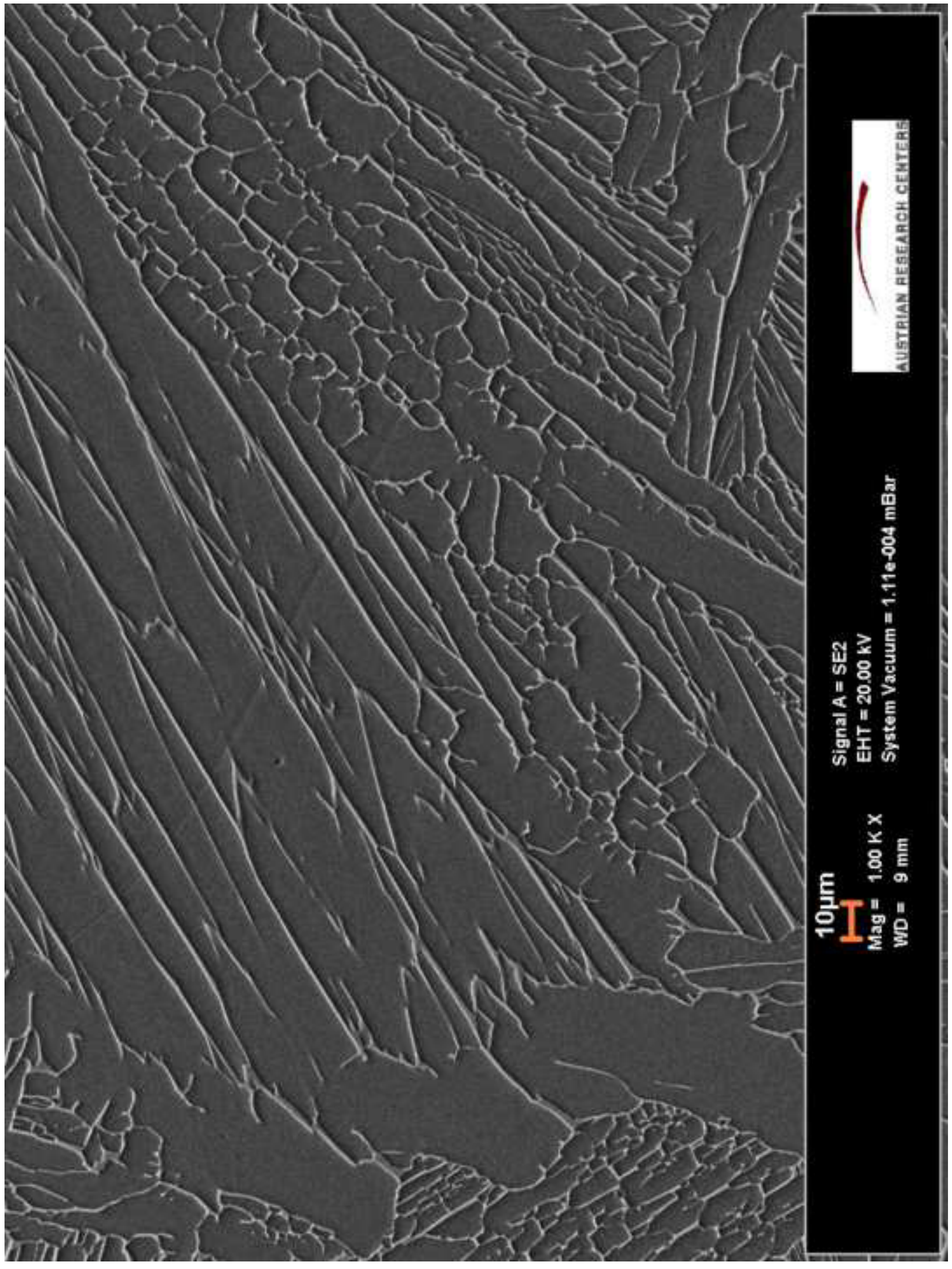




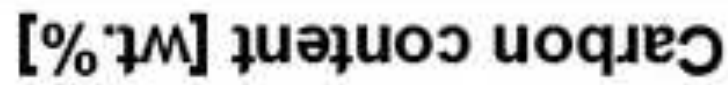

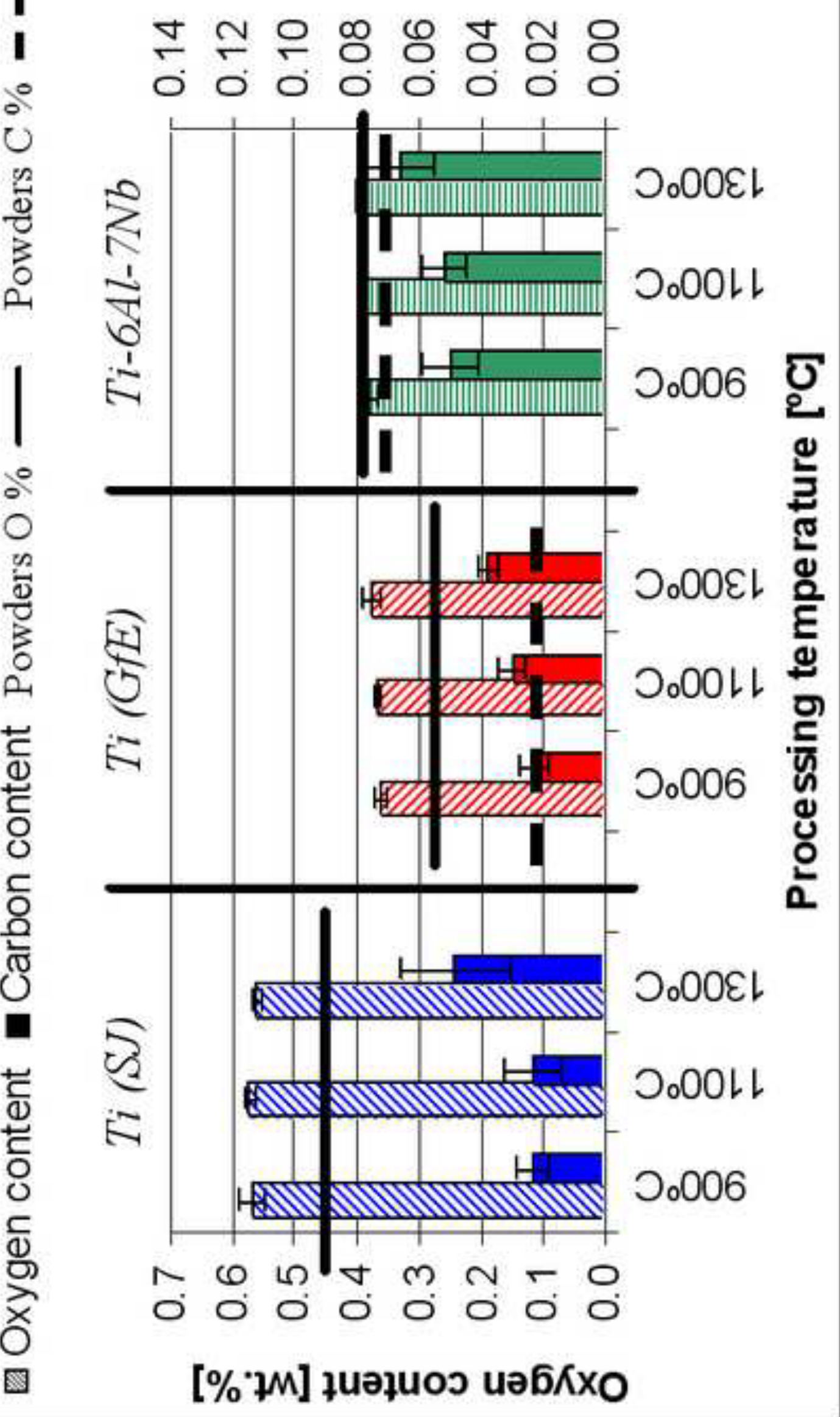




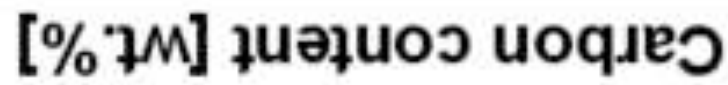

I
I
0
0
0
0
0

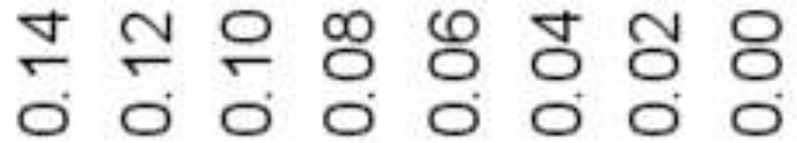

ํ.

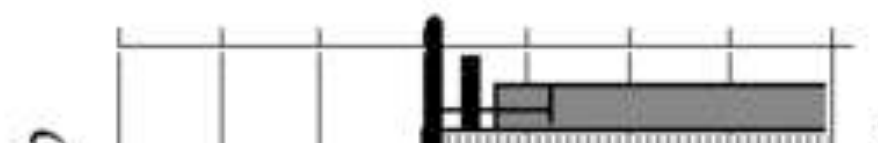

$\stackrel{2}{z}$

¿

हु

| 1

$\therefore$
0
0
$\frac{0}{0}$

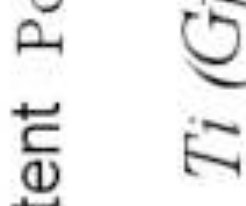

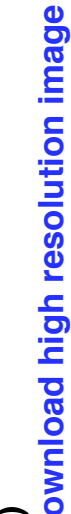

$\xi \frac{c}{c}$

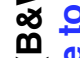

in क्षे

o

.

ว.00ع

O.00LL

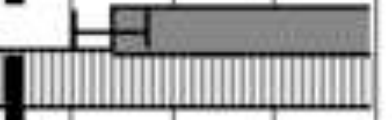

0.006 ర్

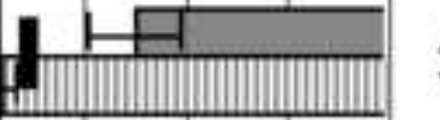

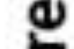
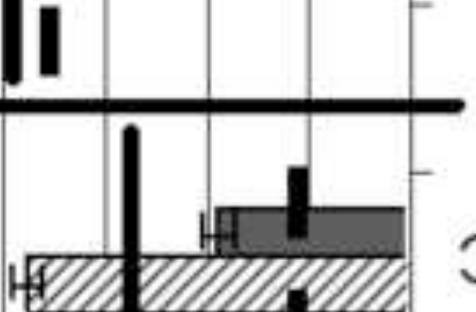

ग.00عL

IT

$\frac{\sqrt{4}}{5}$

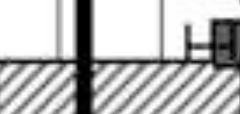

V.III $000 \mathrm{LL}$

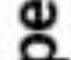

+⿱宀

150

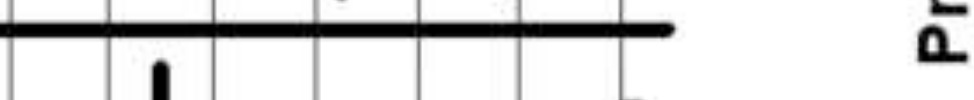

등

-

눙

5

ว.00عL

0.006

需

$\Phi$

芫

0

ฮั

$\stackrel{0}{x}$

ô

N

MoO L L

(1)

。

2. 


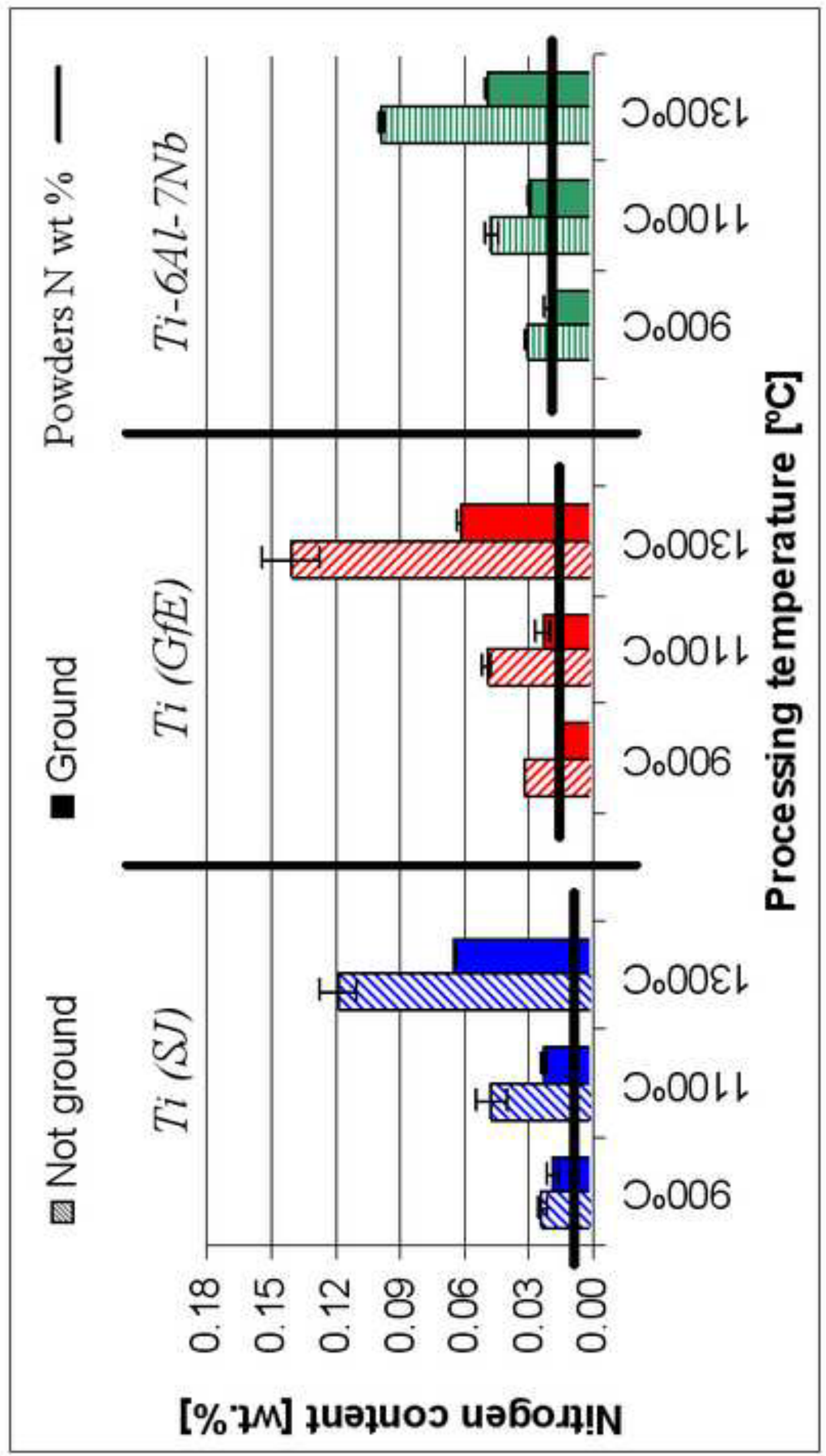




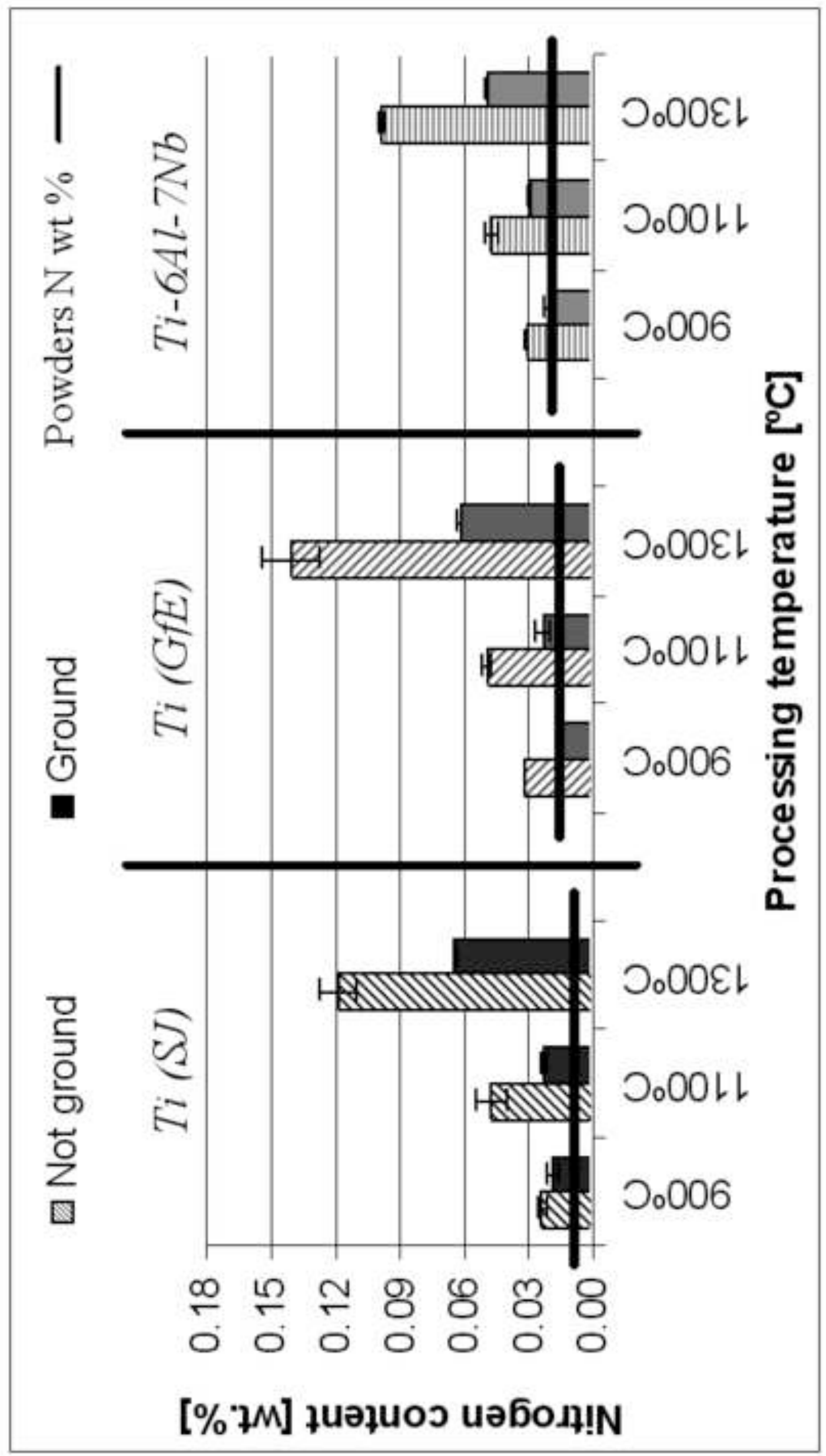

$\xi \frac{1}{3}$

文

(o)

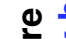

尊 


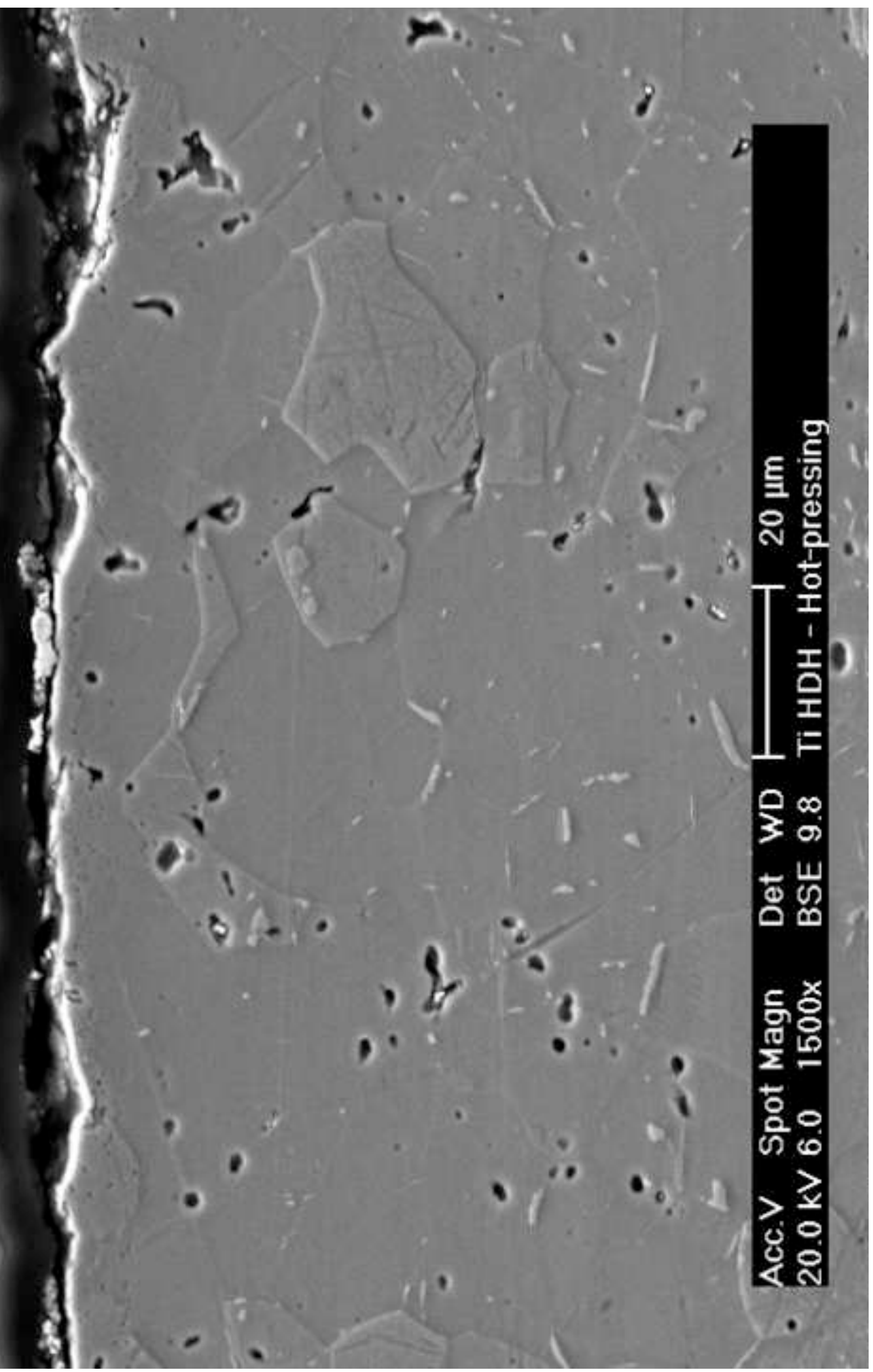

(1)

는 흔 은 


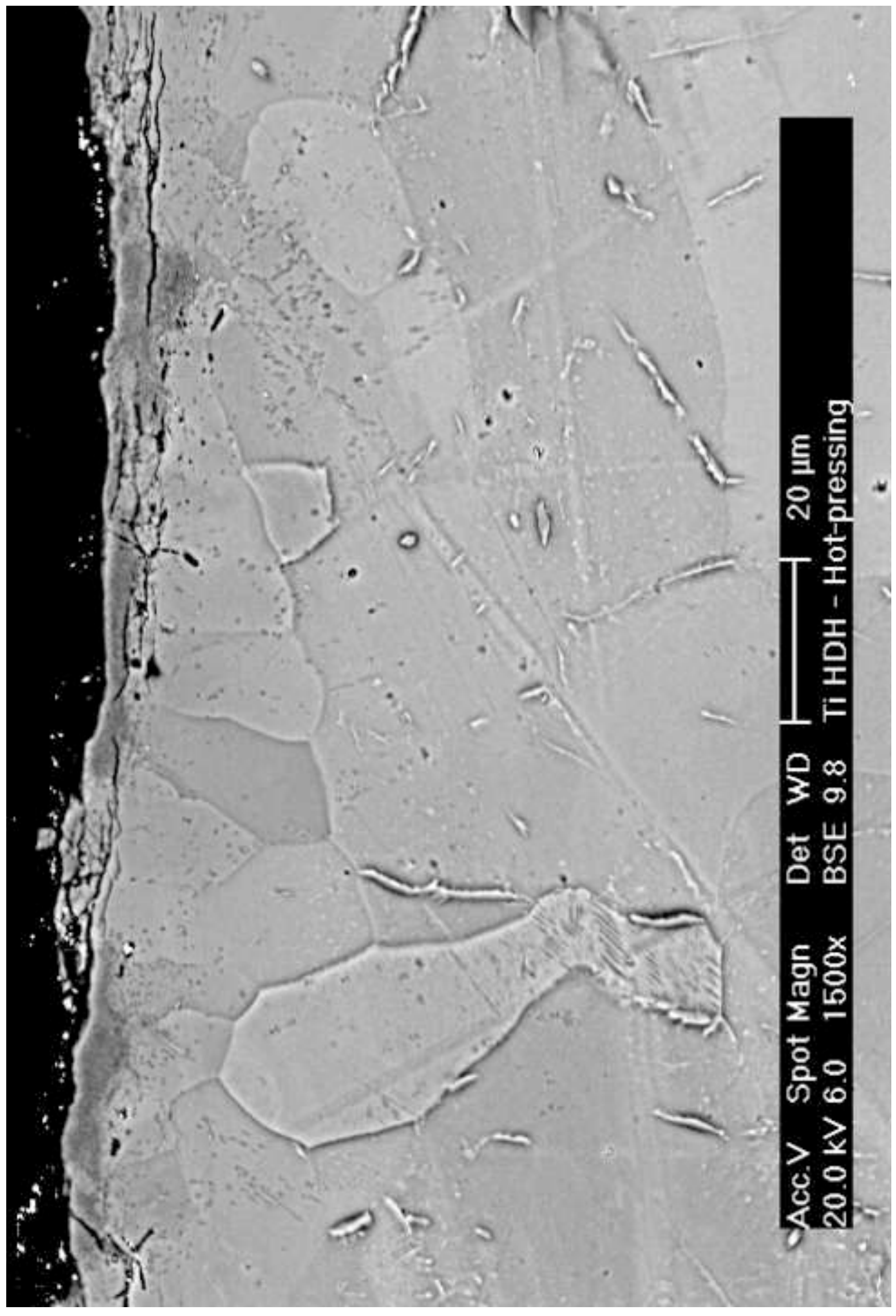

○. 논 


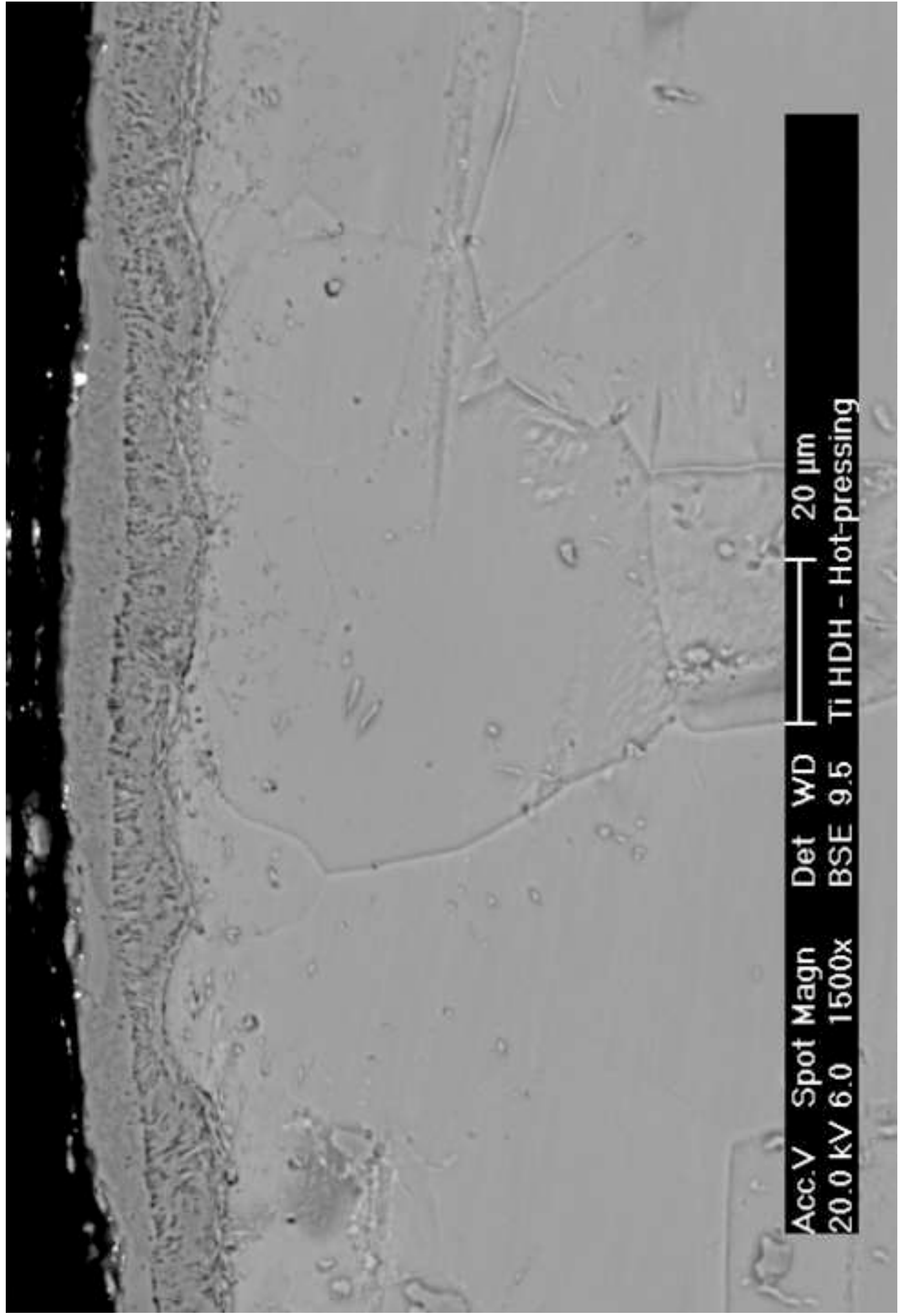

¿

는 은 


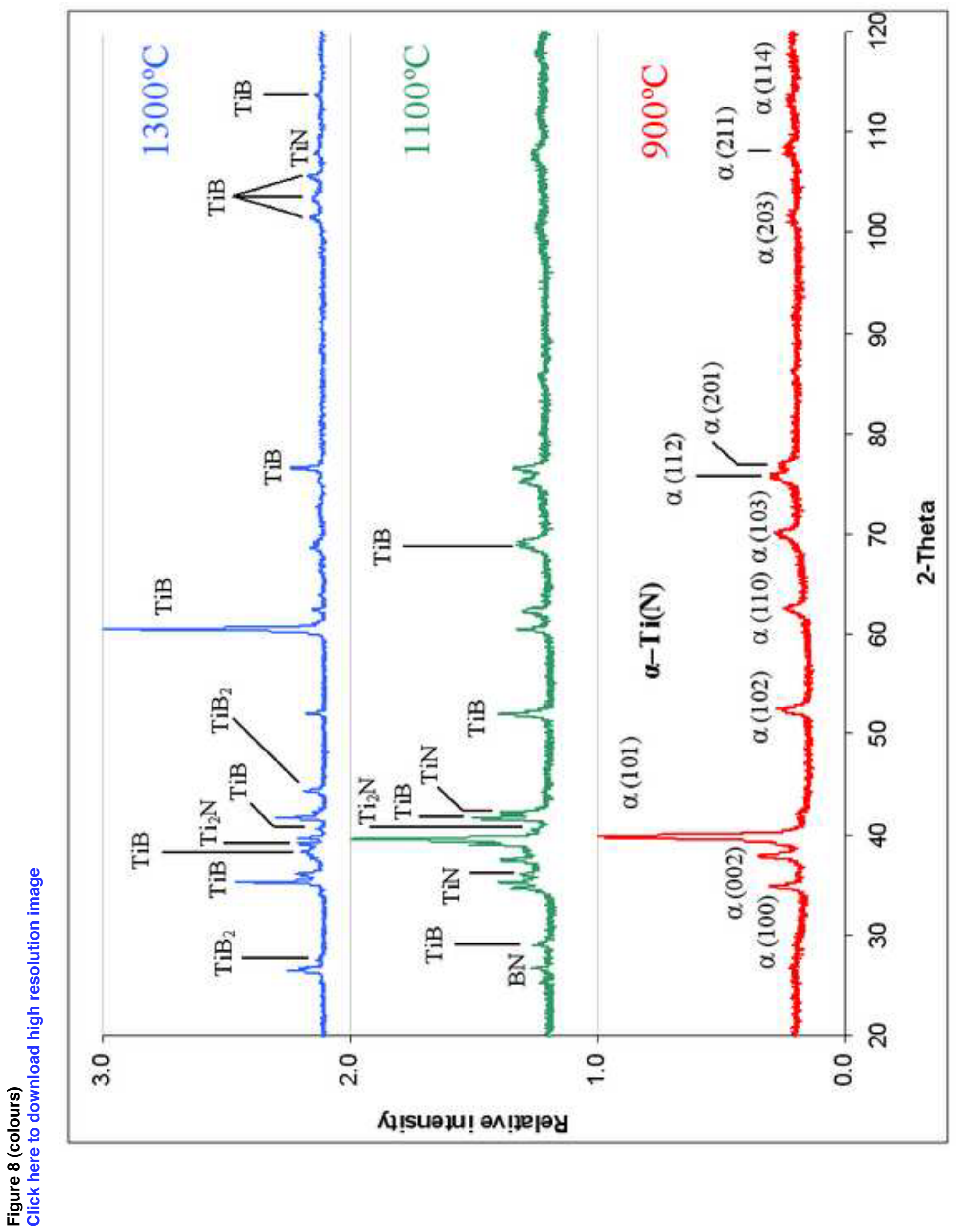




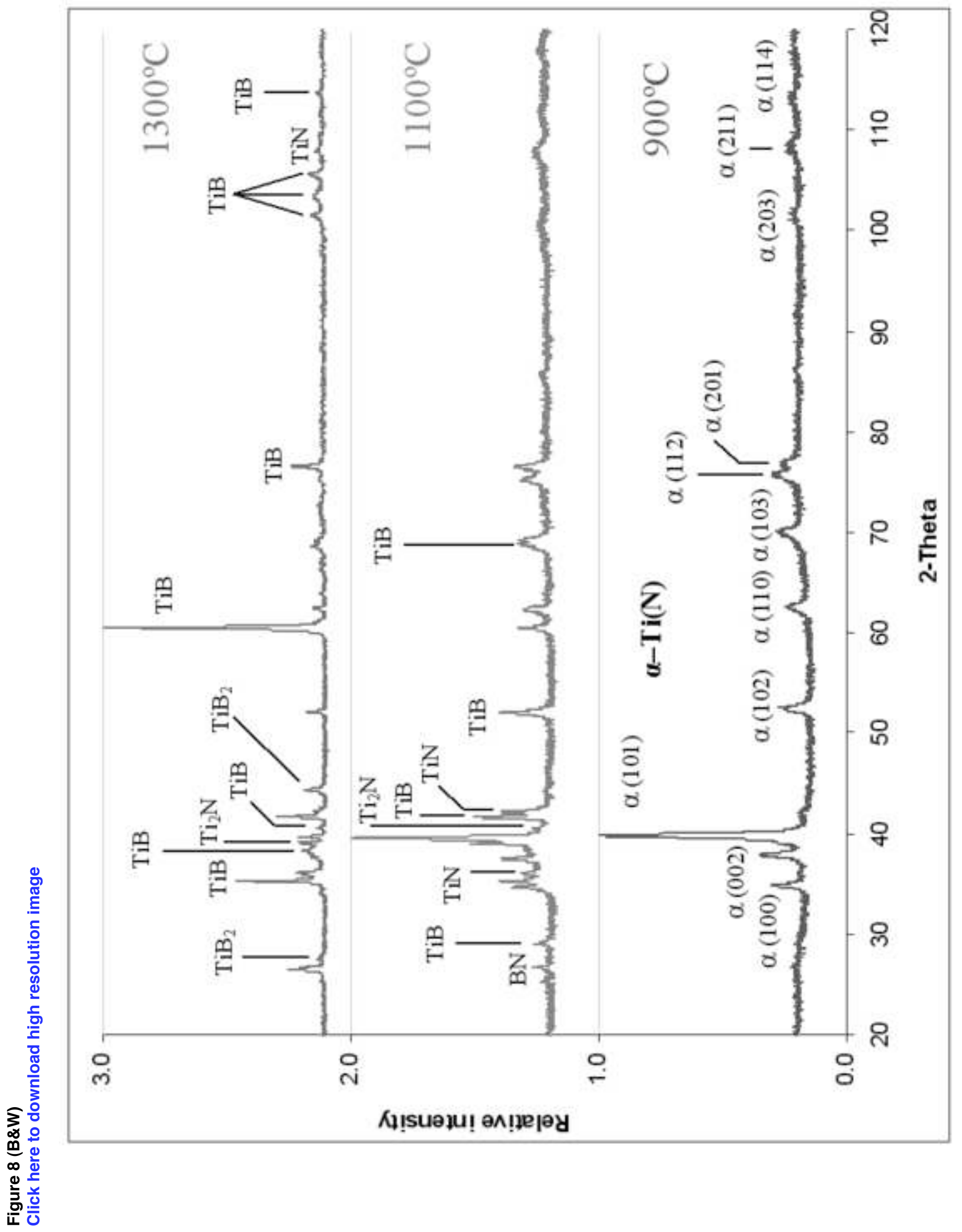




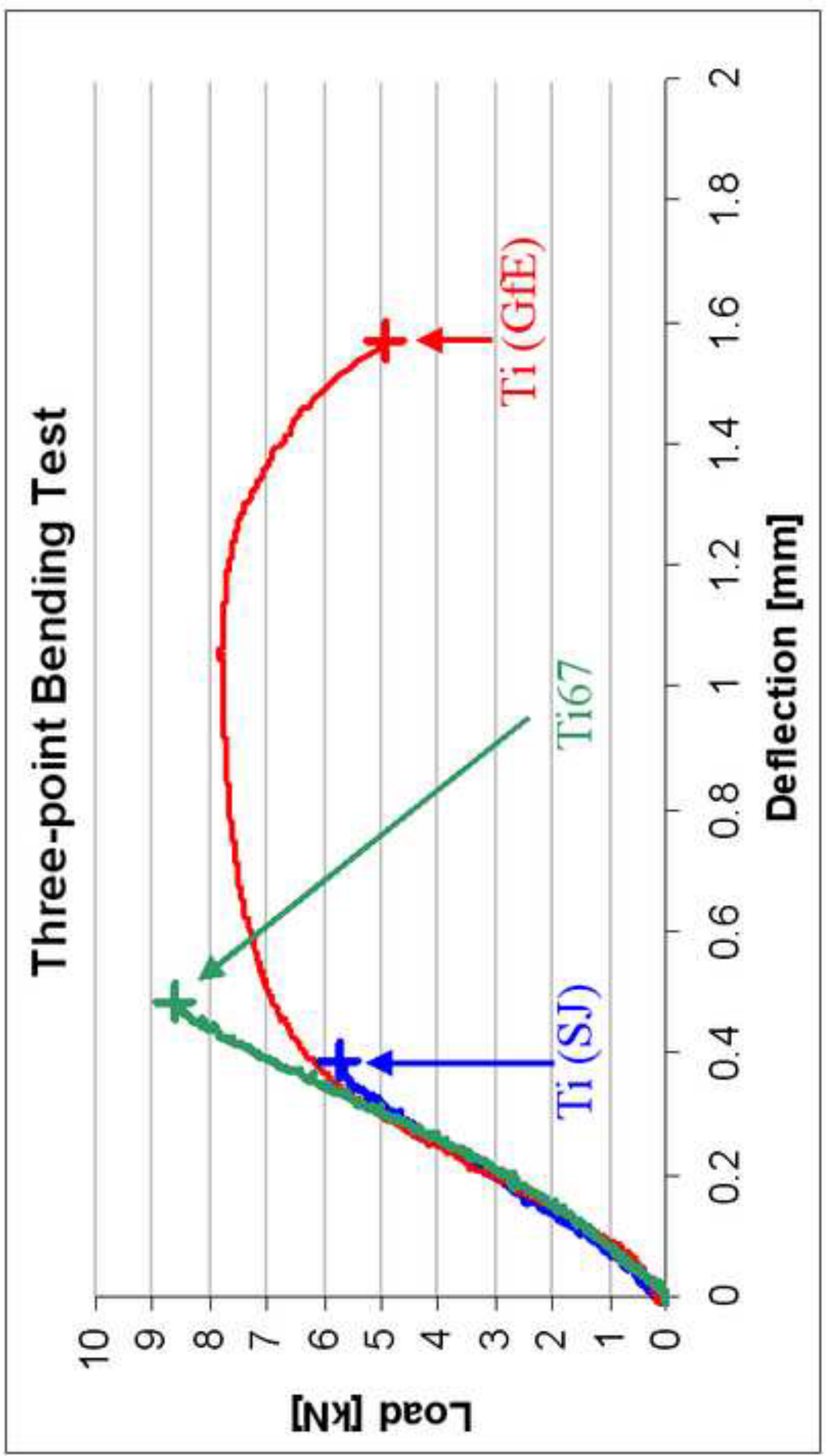

क 후웅 잉 o . go 


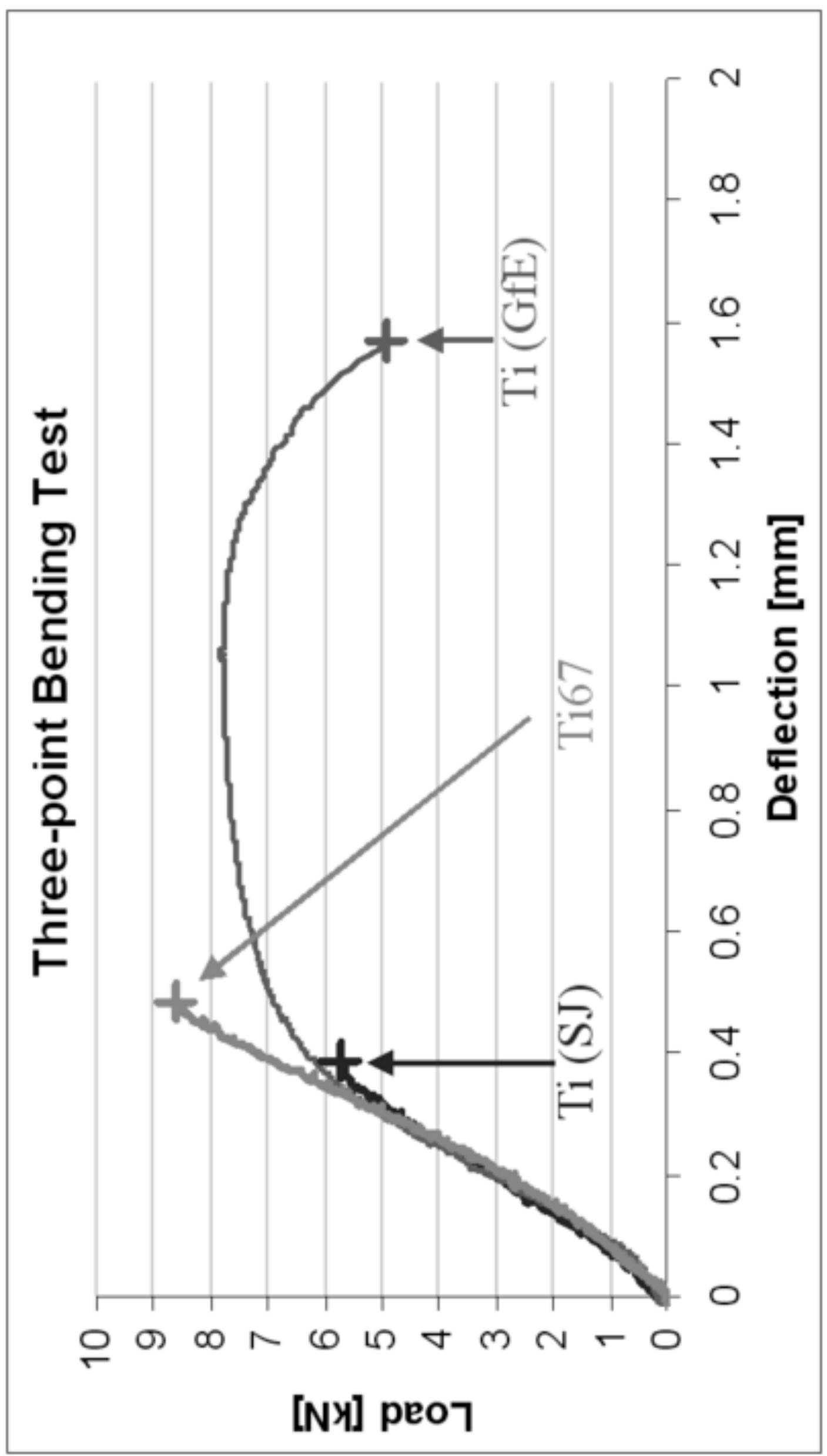




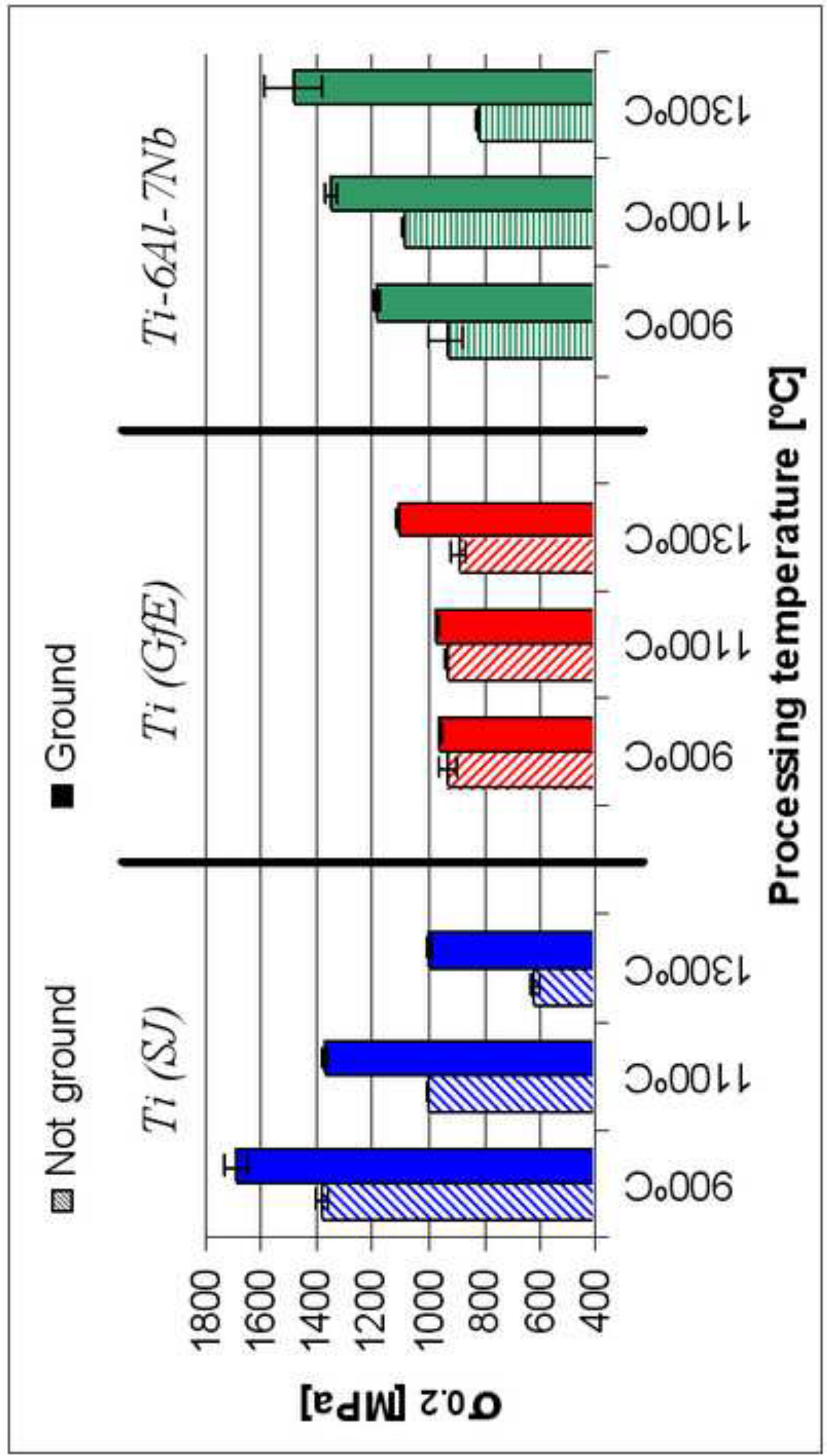

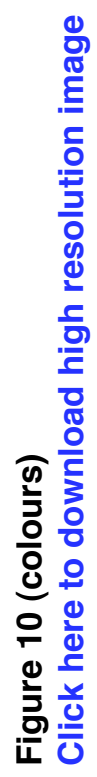




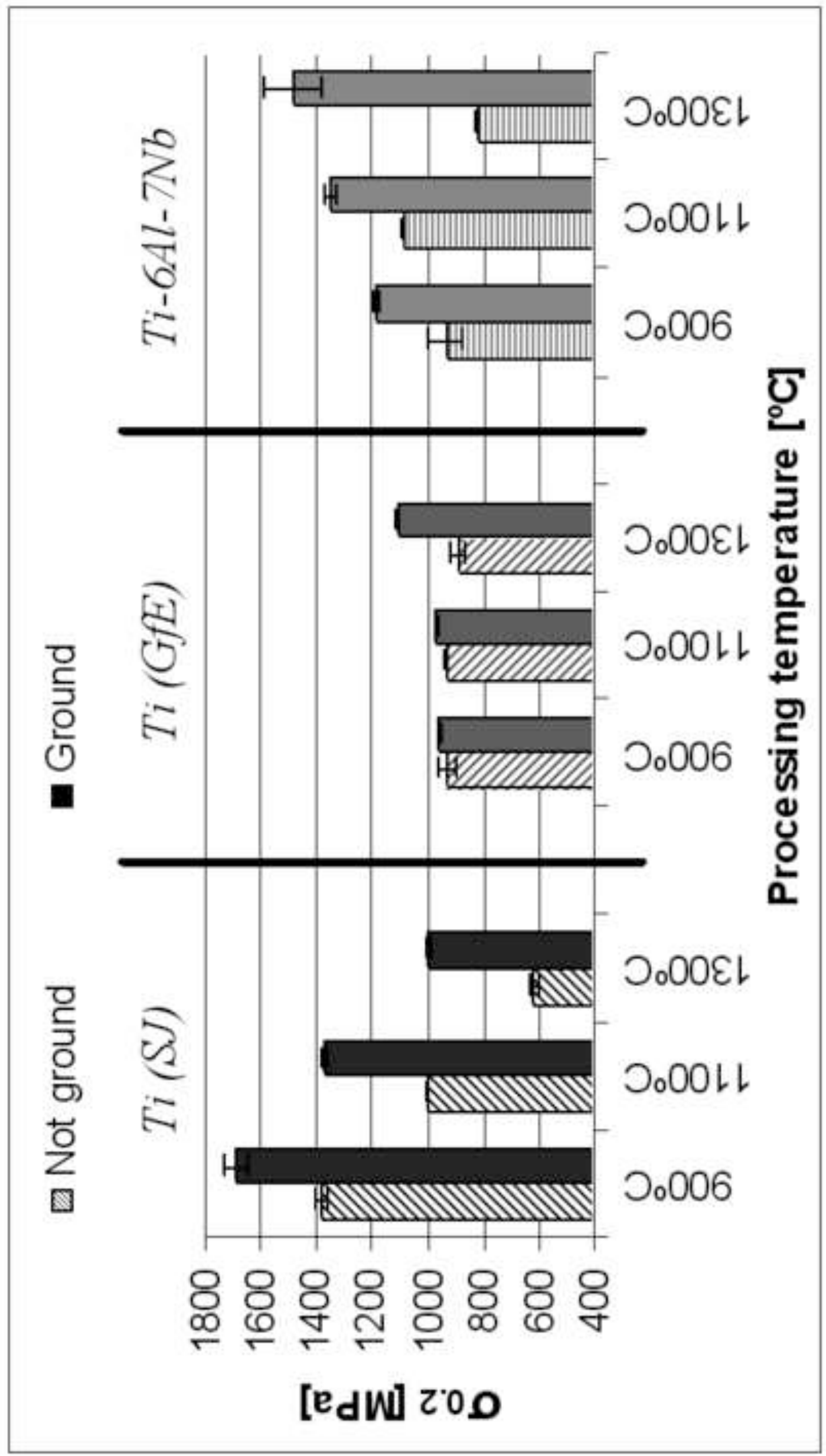

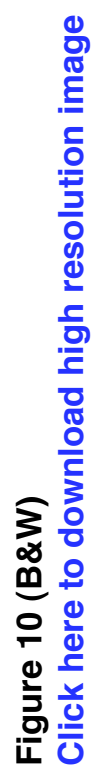




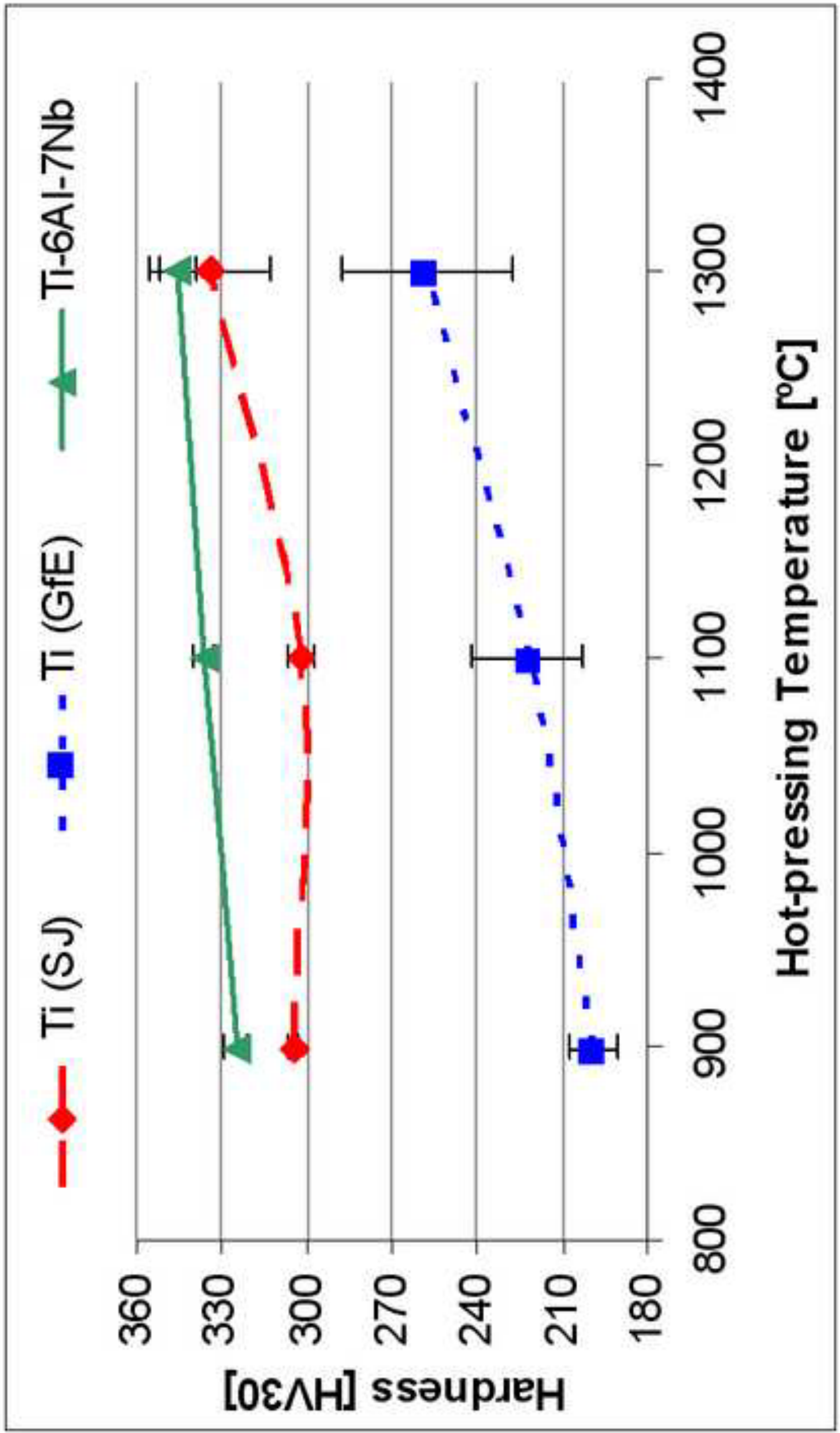

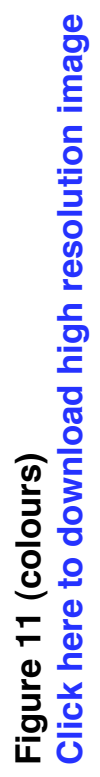




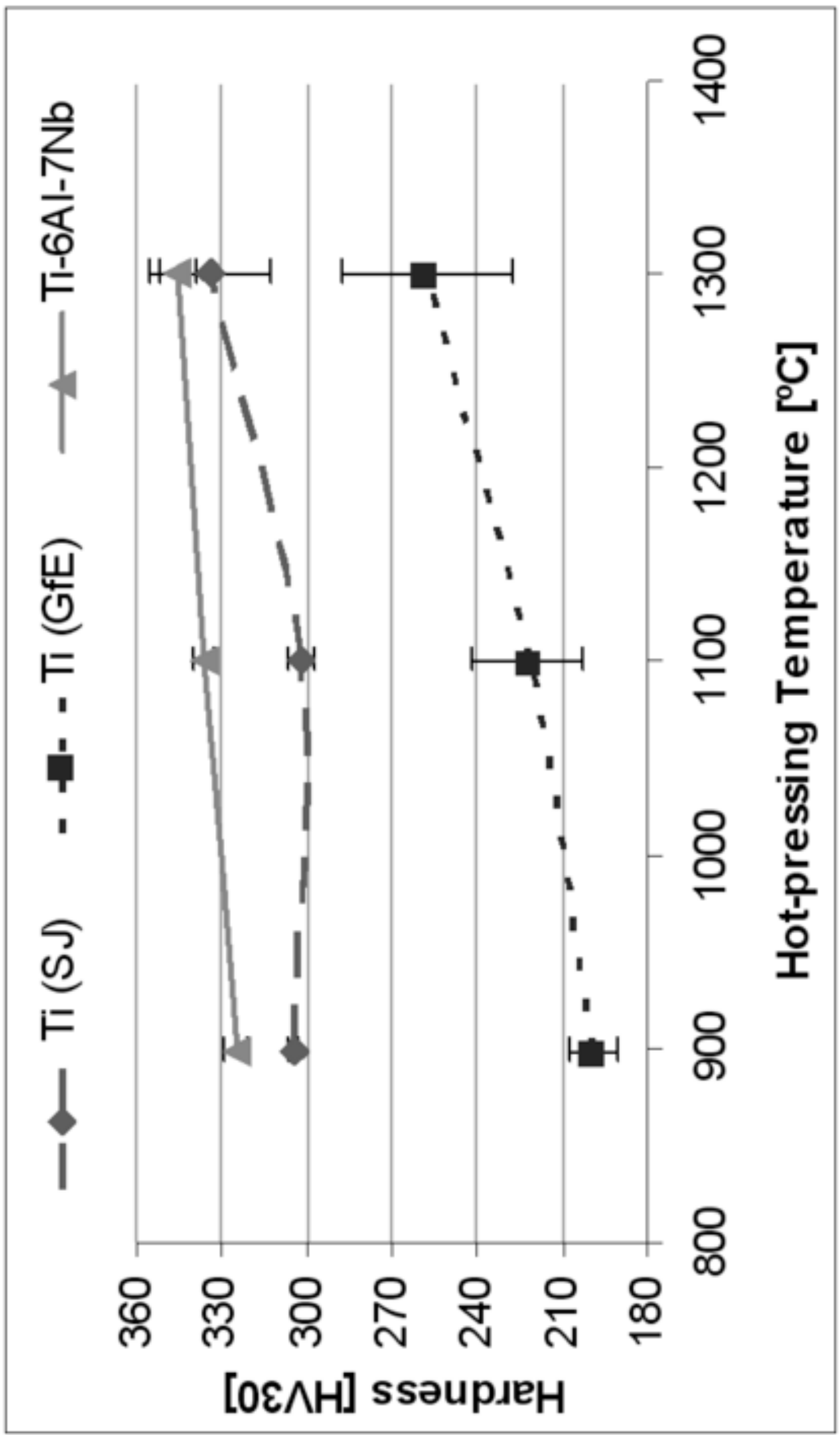

$\stackrel{0}{\sigma}$

$\mp$

인 흔 
Table 1. Particle size distribution and chemical analysis of the starting powders.

\begin{tabular}{|c|c|c|c|c|}
\hline \multicolumn{2}{|c|}{ Material } & Ti (SJ) & Ti (GfE) & Ti-6A/-7Nb \\
\hline \hline \multicolumn{2}{|c|}{ Morphology } & Irregular & Irregular & Irregular \\
\hline \multirow{3}{*}{ Particle size [ $\mu \mathrm{m}]$} & $\mathrm{D}_{\max }$ & $<26^{*}$ & $<75^{*}$ & $<90$ \\
\cline { 2 - 5 } & $\mathrm{D}_{10}$ & $6.19^{*}$ & 17.31 & 17.40 \\
\cline { 2 - 5 } & $\mathrm{D}_{50}$ & $13.19^{*}$ & 37.59 & 40.39 \\
\cline { 2 - 5 } & $\mathrm{D}_{90}$ & $24.68^{*}$ & 72.59 & 81.94 \\
\hline \hline \multirow{3}{*}{ Chemical Analyses [wt. \%] } & $\mathrm{O}$ & 0.450 & 0.272 & 0.393 \\
\cline { 2 - 5 } & $\mathrm{N}$ & 0.0100 & 0.0159 & 0.0173 \\
\cline { 2 - 5 } & $\mathrm{C}$ & - & 0.0202 & 0.0706 \\
\hline
\end{tabular}

* Supplier specifications. 
Table 2. Maximum bending strength and flexural strain of elemental titanium and Ti-6Al-7Nb hot-pressed specimens.

\begin{tabular}{|c|c|c|c|c|c|c|c|}
\hline \multicolumn{3}{|c|}{ Material } & \multicolumn{2}{c|}{ Ti(SJ) } & \multicolumn{2}{c|}{ Ti(GfE) } & \multicolumn{2}{c|}{ Ti-6Al-7Nb } \\
\hline \multirow{3}{*}{$\begin{array}{c}\text { Maximum bending } \\
\text { strength [MPa] }\end{array}$} & $900^{\circ} \mathrm{C}$ & $1456 \pm 15$ & $1687 \pm 42$ & $1304 \pm 27$ & $1289 \pm 76$ & $934 \pm 60$ & $1182 \pm 10$ \\
\cline { 2 - 8 } & $1100^{\circ} \mathrm{C}$ & $1000 \pm 6$ & $1446 \pm 14$ & $1129 \pm 5$ & $1388 \pm 12$ & $1088 \pm 2$ & $1347 \pm 21$ \\
\cline { 2 - 9 } & $1300^{\circ} \mathrm{C}$ & $616 \pm 13$ & $992 \pm 10$ & $906 \pm 34$ & $1369 \pm 24$ & $822 \pm 8$ & $1485 \pm 108$ \\
\hline \hline \multirow{3}{*}{ Flexural Strain [\%] } & $900^{\circ} \mathrm{C}$ & $2.89 \pm 0.30$ & $3.53 \pm 0.05$ & $18.25 \pm 0.65$ & $25.93 \pm 5.72$ & $1.51 \pm 0.06$ & $1.85 \pm 0.13$ \\
\cline { 2 - 8 } & $1100^{\circ} \mathrm{C}$ & $1.63 \pm 0.13$ & $2.51 \pm 0.15$ & $5.63 \pm 0.06$ & $19.89 \pm 2.36$ & $1.99 \pm 0.11$ & $2.30 \pm 0.59$ \\
\cline { 2 - 8 } & $1300^{\circ} \mathrm{C}$ & $1.32 \pm 0.03$ & $1.20 \pm 0.13$ & $2.20 \pm 0.50$ & $6.77 \pm 0.12$ & $1.46 \pm 0.28$ & $2.00 \pm 0.16$ \\
\hline
\end{tabular}

